\title{
Influence of damage versus temperature on modal strains and neutral axis positions of beam-like structures ${ }^{\star, \star \star}$
}

\author{
Dimitrios Anastasopoulos ${ }^{\mathrm{a}, *}$, Guido De Roeck ${ }^{\mathrm{a}}$, Edwin Reynders $^{\mathrm{a}}$ \\ ${ }^{a}$ KU Leuven, Department of Civil Engineering, Kasteelpark Arenberg 40 - box 2448, 3001 Leuven, Belgium
}

\begin{abstract}
Vibration-based Structural Health Monitoring is a non-destructive condition assessment method that exploits damage-related changes in the dynamic characteristics of a structure. The sensitivity of some commonly employed dynamic characteristics such as natural frequencies, to local damage of moderate severity might be lower than their sensitivity to environmental influences such as temperature. Modal strains are more sensitive to local damage, but the accurate dynamic monitoring of the very low strain levels that occur in civil engineering structures under ambient excitation became possible only recently. In this work, the influence of both temperature and damage on modal strains is experimentally investigated for a prestressed concreted beam in controlled laboratory conditions. Not only the modal strains themselves are considered, but also the neutral axis position under bending deformation, which relates directly to the bending stiffness. It is found that the induced temperature changes in the concrete beam do not have a measurable influence on the modal strains and neutral axis positions. The cracks that are induced in the beam by external loading in a progressive damage test do have a clear and local influence on the strain mode shapes and neutral axis positions, even at low damage levels.
\end{abstract}

Keywords: structural health monitoring, dynamic strain sensing, operational modal analysis, strain mode shapes, neutral axis in bending, environmental influences

\section{Introduction}

Civil structures, such as bridges, dams, and tunnels, are designed in order to operate safely and continuously. However, deterioration and damage might appear as they are approaching or even exceeding their original design life, due to their exposure to environmental and operational loads or due to extreme events, such as earthquakes. Therefore, the development and implementation of reliable structural health monitoring (SHM) techniques that provide timely information about the structure's condition becomes necessary $[1,2]$. This information can be elaborated in a decision

\footnotetext{
${ }^{\star}$ Postprint submitted to Mechanical Systems and Signal Processing

${ }^{\star \star}$ Published version: D. Anastasopoulos, G. De Roeck and E. Reynders. Influence of damage versus temperature on modal strains and neutral axis positions of beam-like structures. Mechanical Systems and Signal Processing, 134:106311, 2019. https://doi.org/10.1016/j.ymssp.2019.106311

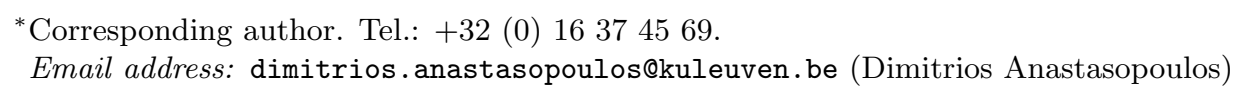


support system, for example, for deciding whether or not maintenance is necessary or if the operational life of a structure can be extended beyond its original design service life, offering multiple safety and economic benefits $[1,3]$. SHM systems can be introduced to structures at any phase of their service life, and their structural condition at the moment of the implementation of the SHM system serves as the baseline condition. Incremental damage can then be identified by comparing future observations with the baseline observations. Thus, an early installed SHM system increases the chances of damage identification at any moment of the structure's service life. For this reason, SHM systems are also deployed right after construction [4].

Vibration-Based Structural Health Monitoring, usually abbreviated as VBSHM or VBM, can be a successful non-destructive approach for damage identification and condition assessment of civil structures $[5,6]$. The idea behind VBSHM is to identify changes in dynamic characteristics of a structure that are directly related to damage $[5,6,7]$. The main challenge for VBSHM is to identify characteristics that are as sensitive as possible to structural damage and at the same time as insensitive as possible to measurement noise, loading, and environmental factors such as temperature $[7,8]$. Natural frequencies are probably the most commonly used dynamic characteristics for damage identification $[8,9,10,11,12]$. However, natural frequencies are influenced by environmental factors, such as temperature, and that influence can be high enough to completely mask the presence of even severe damage, necessitating data normalization $[6,13,14,15]$. A promising alternative is the monitoring of modal strains (also termed strain mode shapes), modal curvatures and related features from dynamic strain measurements, as these characteristics are more sensitive to local damage than most other dynamic characteristics $[16,17,18,19]$.

However, the dynamic strains that occur in civil structures in normal operational conditions usually have a very low amplitude, typically lower than 1 microstrain $(1 \mu \mathrm{m} / \mathrm{m})$. This renders the accurate identification of modal strains from response-only data challenging, even when fiber-optic sensors are used [20]. Two alternative approaches have been recently developed to increase the accuracy of strains obtained from Fiber Bragg Grating (FBG) sensors, which can be multiplexed along a glass fiber for yielding a dense measurement grid at relatively low cost, to sub-microstrain level. The first approach consists of replacing the standard wavelength shift detection algorithm in a commercial broadband FBG interrogator with a more advanced optical signal processing algorithm [21]. In the second approach, a tunable laser FBG interrogator is employed for scanning each FBG sensor individually with a wavelength sweep. This approach offers a high wavelength resolution but it also introduces a phase shift in the identified modal strains, which can be compensated for as discussed in [19]. Thanks to these developments, operational modal analysis [22] from ambient dynamic strains measured on large civil structures is now feasible.

Two additional and so far little explored aspects of operational (modal) strain monitoring are investigated in the present article. Firstly, a strain-based damage sensitive feature is sought that can be directly related to structural damage. For structures that undergo bending deformation, the neutral axis position can be derived from strain measurements at the top and bottom of a cross section. Pure bending deformation is hard to achieve by direct excitation, but (operational) modal analysis allows for separating bending modes from other modes. This is fully explored in the present work. A second contribution is a thorough experimental investigation of the influence of damage versus temperature on strain mode shapes and the related neutral axis position under bending deformation. This is performed in a controlled laboratory setting, where a prestressed concrete beam is progressively damaged by applying it to loading-unloading cycles of increasing load amplitude in a four-point bending test. After each unloading the beam is subjected to permanent dynamic strain monitoring, while the ambient temperature is varied. 
The remainder of this article is organized as follows. In section 2, the monitoring of modal strains and neutral axis positions and their physical significance are discussed. Section 3 contains a detailed description of the experimental setup that has been used for investigating the influence of damage versus temperature on these quantities. Next, in section 4 , the experimental results are presented and explored. Concluding remarks are provided in section 5 .

\section{Dynamic monitoring of macrostrains and neutral axis positions}

The physical quantities that are monitored in the present paper are dynamic strains, which are processed into strain mode shapes. The measured strains are in fact macrostrains: relative displacements between two points on a structure that are separated by a (macroscopically) finite distance, typically a few centimeters to a few meters. Although some investigations into the dynamic monitoring of macrostrains have already been performed [18, 23, 24], their further processing into quantities that are directly related to structural load bearing capacity, such as the neutral axis position under bending, has not yet been thoroughly explored. In the remainder of this section, the monitoring of strains and neutral axis positions at the macroscopic level, and the physical significance of these quantities, is discussed in detail.

\subsection{Influence of structural damage on bending deformation}

Let us first consider a (macroscopically finite) element of an undamaged beam-like structure, such as a bridge. When this element is subjected to pure bending, a neutral plane exists in the longitudinal direction, and the material inside that plane is neither elongated nor compressed. The material outside of the neutral plane is either compressed or elongated. The intersection between the neutral plane and a cross section is called the neutral axis in bending. Fig. 1a illustrates this for an I-shaped beam element. In most cases, the bending deformation is very well approximated by the Euler-Bernoulli hypothesis, which states that plane cross sections before deformation remain plane and normal to the beam's axis after deformation. Differently formulated, this means that within a cross section, the longitudinal strain varies linearly with the distance from the neutral axis. Strain sensors, such as a fiber Bragg gratings (FBG), can be employed for measuring the average longitudinal strain (or macrostrain) of the considered beam element, by connecting them to the beam element at both ends. If two such sensors are employed, one at a distance $d$ from the top and one at a distance $d$ from the bottom of the element, and the strains under bending, $\epsilon_{\text {top }}$ and $\epsilon_{\text {bot }}$, can be determined from these sensors, then the vertical distance of the neutral axis under bending deformation from the geometrical center of the beam, $z_{\mathrm{N}}$, can be determined as:

$$
z_{\mathrm{N}}(x)=\frac{\epsilon_{\mathrm{bot}}(x)(H-2 d)}{\epsilon_{\mathrm{bot}}(x)-\epsilon_{\mathrm{top}}(x)}-\frac{H}{2}+d,
$$

where $H$ is the height of the beam and $x$ is the nominal longitudinal position of the beam element. For simplicity, it has been assumed that the cross-section is symmetric with respect to the vertical axis and the distance $d$ is the same for the top and bottom strain sensor, however, the analysis can be straightforwardly extended if this is not the case. Eq. (1) can be easily derived from geometrical considerations, as illustrated in Fig. 1 for an undamaged and damaged steel beam.

Suppose now that the considered beam element is damaged at the bottom in a uniform way along its length. This may happen for example when the element is made of steel and is uniformly corroded along its length at the bottom over a certain zone of the cross section, as in Fig. 1b. The 


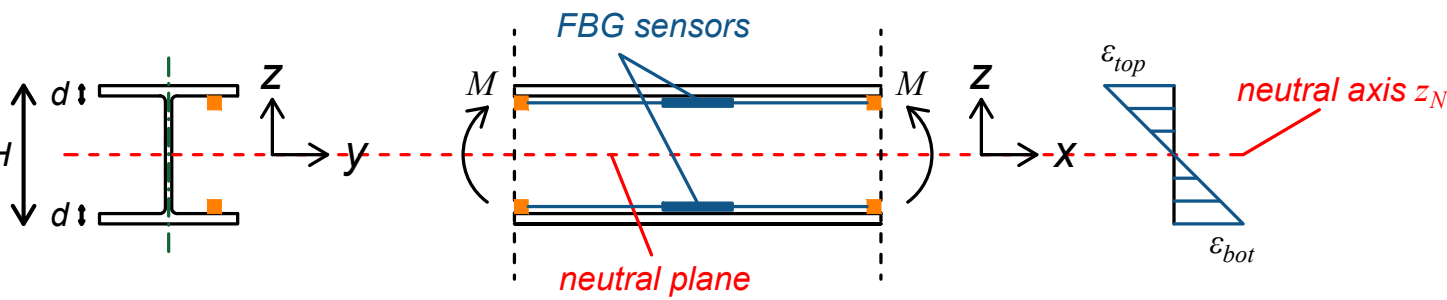

(a)

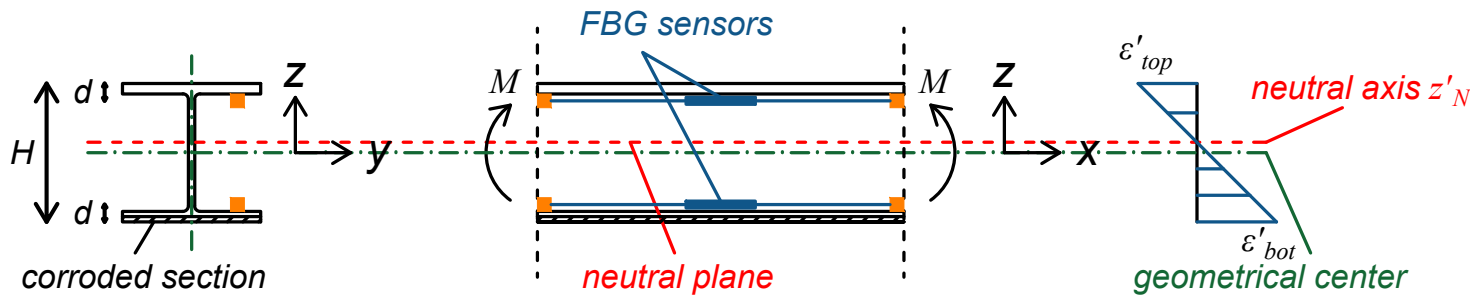

(b)

Figure 1: Graphic representation of the strain distribution and the location of the neutral axis for a steel beam with I-shaped cross-section, (a) in undamaged condition and (b) with part of the bottom flange corroded. The orange cubes are connectors for attaching strain sensors to the beam element. In this example, the strain sensors are optic fibers with Bragg gratings inscribed.

beam element has now lost its stiffness over this zone such that, when subjected to bending again, the load is taken by the undamaged zone of the cross section, and the neutral axis has shifted with respect to the undamaged situation. When the macrostrain measurement is repeated, the new neutral axis position can be determined. The magnitude of the neutral axis shift is directly related to the loss of stiffness.

The situation gets more complex when the element is damaged locally. Suppose for example, that the element is made of reinforced concrete and cracked at the bottom at several locations, as in Fig. 2. Then the local (micro)strains close to the crack deviate from what would be predicted by the Euler-Bernoulli hypothesis. However the hypothesis can be expected to hold with good accuracy when macrostrains are considered over a zone that spans at least one, and preferably several, cracks, as in such case the effect of the cracks is smeared out, thanks also to the interaction (bonding) between the concrete and the tensile reinforcement, as illustrated in Figs. 2b and c. In this context, it can be noted that structural models based on the Euler-Bernoulli hypothesis underpin widely used models for structural design of reinforced and prestressed concrete beams [25, 26]. Just as in the previous case with uniform damage, the cracks result in a shift of the neutral axis (or more precisely, the average neutral plane position over the length of the macroscopic element).

For prestressed concrete elements, the situation will be the same as for reinforced concrete elements, except that when the prestressing forces are not symmetric with respect to the geometrical center of the cross section, neither is the neutral axis position in undamaged condition. Furthermore, in damaged condition, the position of the neutral axis depends on the load level. At high levels of loading, the cracks are open and the neutral axis shift is substantial. When the loading is lowered, the cracks will be partially closed by the prestressing forces, and the shift of the neutral axis with respect to the undamaged case is reduced.

\subsection{Identification of neutral axis position using operational modal analysis}

In principle, macro-strain measurements for the determination of the neutral axis position can be performed with a suitable (quasi-)static loading experiment [27, 28]. However, performing 


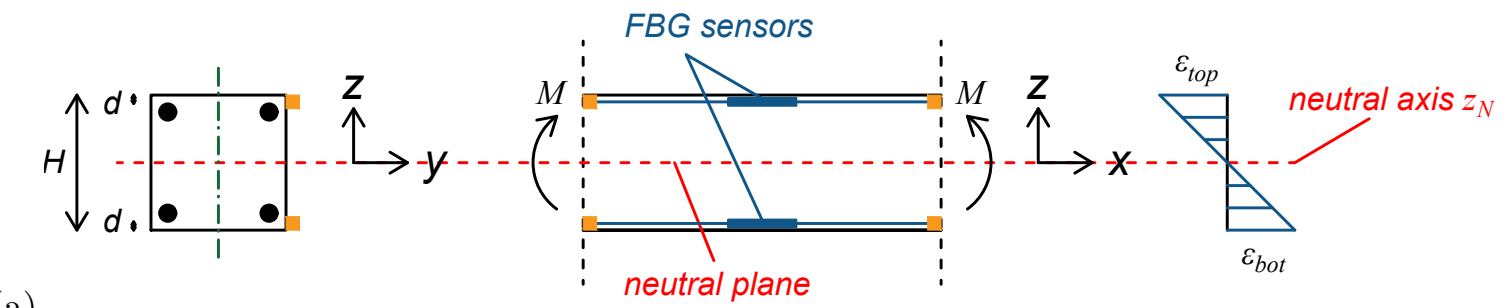

(a)

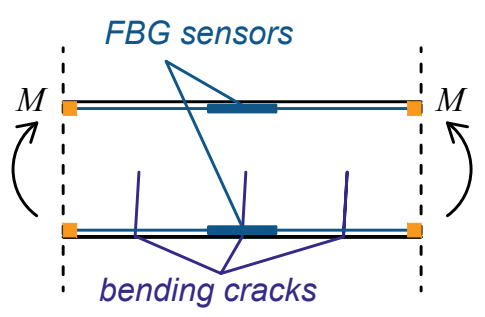

(b)

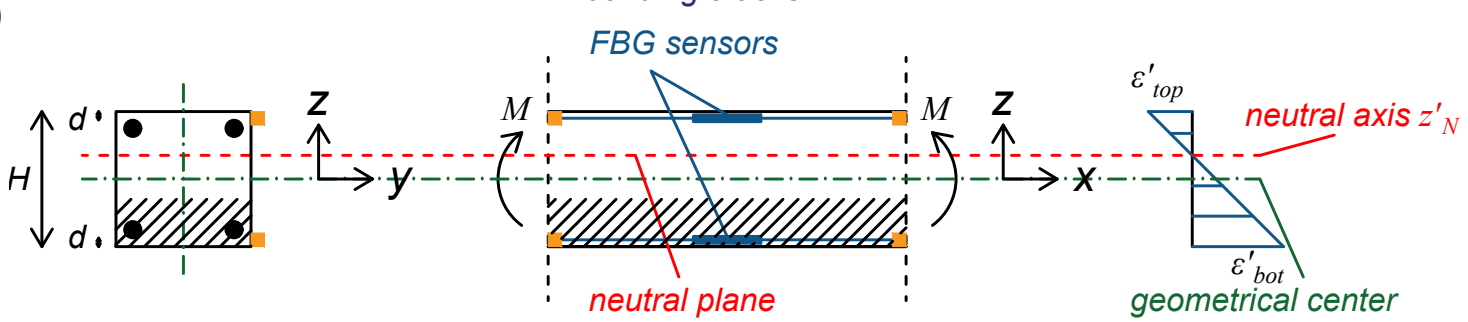

(c)

Figure 2: Graphic representation of the strain distribution and the location of the neutral axis for a reinforced concrete (RC) beam with rectangular cross section. (a) Undamaged beam, (b) damaged beam (localized cracks) and (c) smeared crack model with macroscopically equivalent deformation as in (b). The orange cubes are connectors for attaching strain sensors to the beam element. In this example, the strain sensors are optic fibers with Bragg gratings inscribed.

structural health monitoring of large civil engineering structures in this way is cumbersome, since the structure needs to be put out of service during the test, the load has to be well controlled in order to generate pure bending deformation, etc. Direct dynamic output-only testing, i.e., measuring the dynamic response of the structure due to operational excitation, is an attractive alternative, yet in this case the excitation of the structure can not be controlled, and vertical bending deformation can mix up with torsional deformation or lateral deformation.

For this reason, a more indirect approach is proposed here. It consists of dynamic output-only testing, but followed by an operational modal analysis (OMA) step [22] before computing the neutral axis position. OMA allows extracting modal characteristics - in the present case natural frequencies, damping ratios and strain mode shapes - from measured response data under mild assumptions regarding the unknown ambient excitation. The strain mode shapes representing vertical bending deformation can subsequently be selected, upon which the neutral axis position can be computed.

\section{Experimental setup}

In the remainder of this paper, the methodology that was outlined in the previous section is tested on a prestressed concrete beam that is subjected to a progressive damage test (PDT) until failure. In between two applied damage stages, the static load is removed, an OMA test is performed, and the strain mode shapes and neutral axis positions along the length of the beam 
are computed. The influence of temperature is also investigated in detail. Despite the apparent simplicity of the test structure, it actually represents a very challenging case for the proposed methodology. This is due to the very low self weight of the beam and the fact that the OMA tests are performed in unloaded condition. As a result, the prestressing strands largely close the cracks in the concrete when the static load is being removed, and the dynamic stiffness in unloaded condition is not very much different from the one in the undamaged case. In large beam-like structures such as bridges, for structural beam members which carry permanent loads, or for reinforced rather than prestressed beam-like structures, the difference between quasi-static and dynamic stiffness in the cracked situation is much smaller than in the present case, and so the proposed methodology has a much higher chance of detecting damage in an early stage.

\subsection{Test structure}

A prestressed concrete beam serves as test structure (Fig. 3). The length of the beam is $5.0 \mathrm{~m}$ and it has a rectangular cross-section of $24 \times 20 \mathrm{~cm}$ with chamfered edges (Fig. 4). Highstrength concrete (HSC) of the category C70/85 was used. The longitudinal reinforcement of the beam consists of 5 prestressed low relaxation strands with a nominal diameter of $12.5 \mathrm{~mm}$ and characteristic tensile strength $\sigma_{\mathrm{pk}}=1860 \mathrm{MPa}$. Three strands are positioned at the bottom of the beam and two at the top (Fig. 4). Since premature cracking is not desired, the described longitudinal reinforcement with prestressed strands is adopted also at the top of the beam. The strands are given an initial stress of $\sigma_{\mathrm{p} 0}=744 \mathrm{MPa}$. Closed-loop stirrups, with a nominal diameter of $6 \mathrm{~mm}$ and a centre-to-centre distance of $150 \mathrm{~mm}$ are provided to withstand the shear forces (Fig. 4). The mass of the beam is $m=580 \mathrm{~kg}$ and the density is $\rho=2435 \mathrm{~kg} / \mathrm{m}^{3}$.

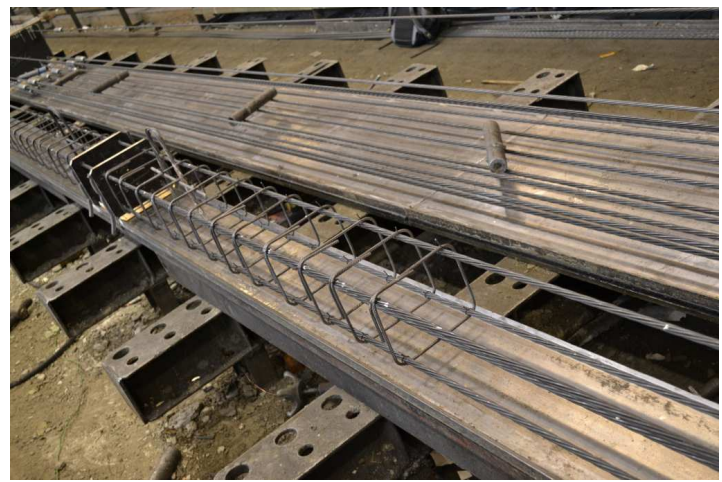

(a)

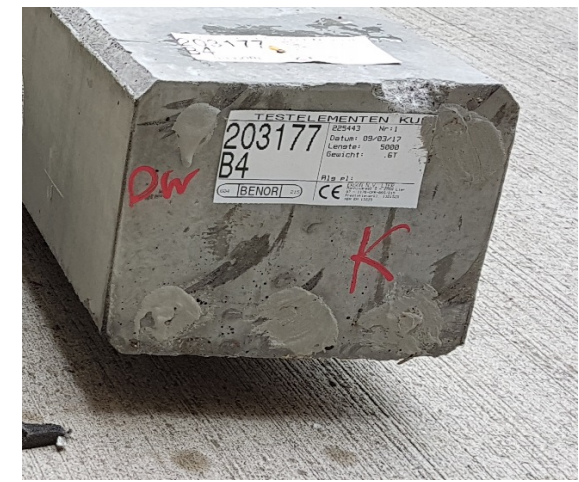

(b)

Figure 3: Prestressed concrete test beam: (a) prestressing strands and stirrups before casting the concrete, and (b) the cross section of the beam with chamfered edges.

\subsection{Quasi-static progressive damage test}

The beam is subjected to a 4-point progressive damage test (PDT). The static boundary conditions approximate these of a simply supported beam. The static steel roller supports are at $50 \mathrm{~cm}$ from the ends of the beam (Fig. 5a). The quasi-static load is applied through two hydraulic jacks (Fig. 5b), controlled with a hydraulic pump which is operated manually, at two points located 1.0 $\mathrm{m}$ respectively from the center of the beam, as shown in Fig. 6. Therefore, a zone of constant bending moment is created in between the two hydraulic jacks, where most of the bending cracks 


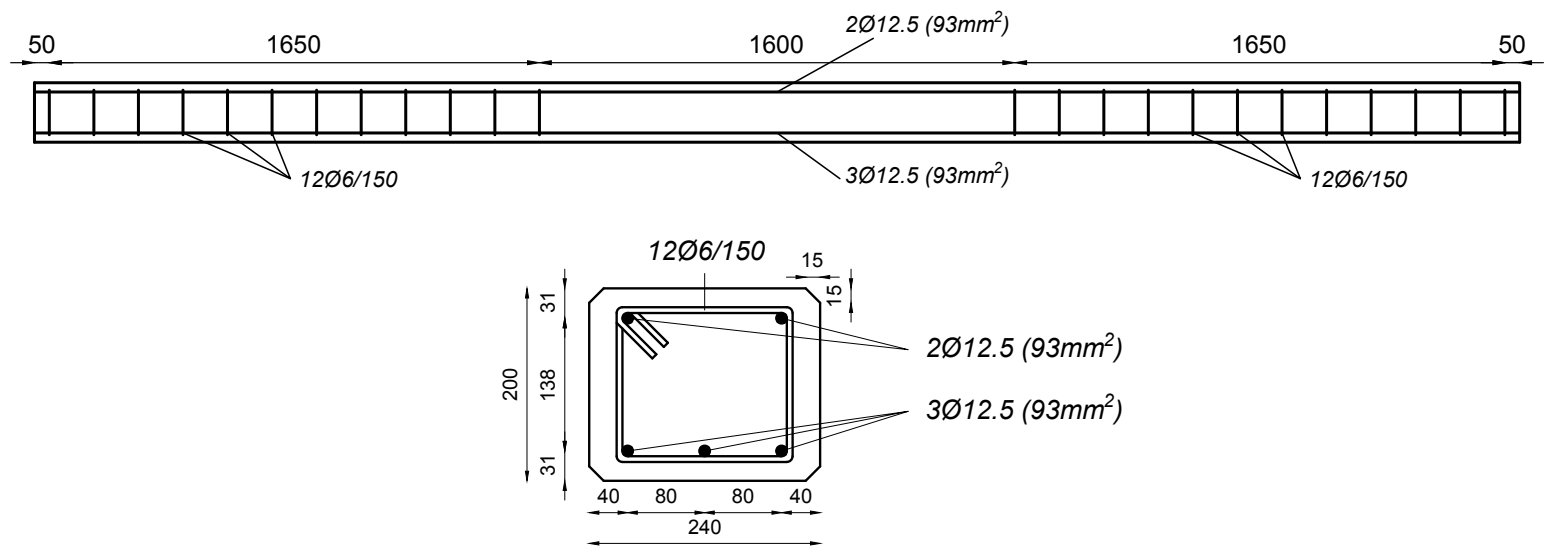

Figure 4: Prestressed concrete test beam: longitudinal and transversal cross sections (dimensions in mm).

are expected during the PDT. The load that is applied to the beam is measured with two load cells, placed between the beam and the tip of the hydraulic jacks (Fig. 5b). Five linear variable differential transformers or LVDTs are used to measure the vertical displacements of the beam at the location of the static supports (2 LVDTs), at the locations where the quasi-static load is applied (2 LVDTs) and at the middle of the beam (1 LVDT), as shown in Fig. 5c and illustrated in Fig. 7. An overview of the complete setup of the PDT is displayed in Fig. 8.

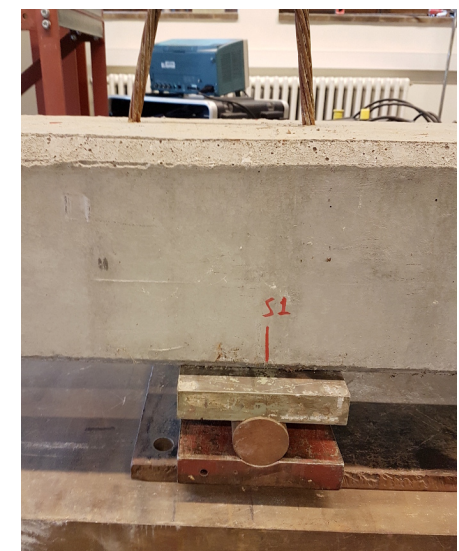

(a)

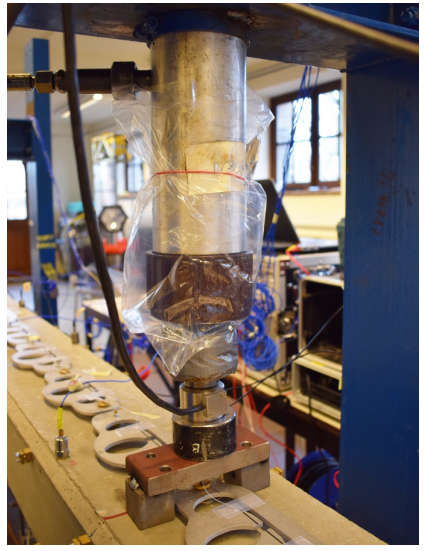

(b)

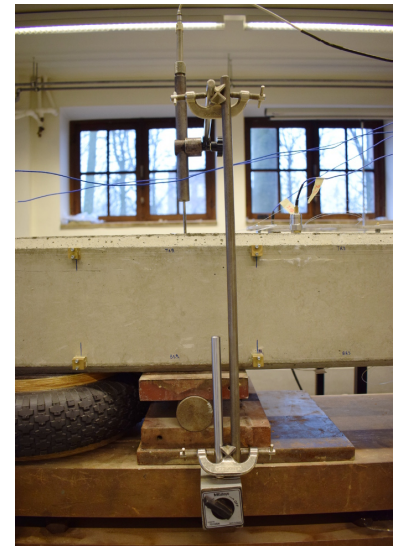

(c)

Figure 5: Progressive damage test setup: (a) static roller support, (b) hydraulic jack and load cell, and (c) LVDT measuring the support displacement.

A quasi-static loading-unloading scheme is followed, consisting of 9 loading cycles of progressively increasing maximal load, where the load step is $2 \Delta P=30 \mathrm{kN}$ for the first 2 cycles and $2 \Delta P=10 \mathrm{kN}$ from the third cycle on, with $\Delta P$ representing the increment in maximum force $P$ that is exerted by a single hydraulic jack (Fig. 6). The beam failed during the $9^{\text {th }}$ loading cycle for a load of $2 \mathrm{P} \approx 160 \mathrm{kN}$. The type of the failure was crushing of the concrete in the middle of the beam due to buckling of the compressive zone, which resulted from the combination of the large deflections due to the static loading and of the high compressive stresses due to the prestressing forces. The beam after its failure is shown in Fig. 9. The maximum deflections measured by all LVDTs and are displayed in Fig. 10a for all loading cycles. The deflections of the last loading 


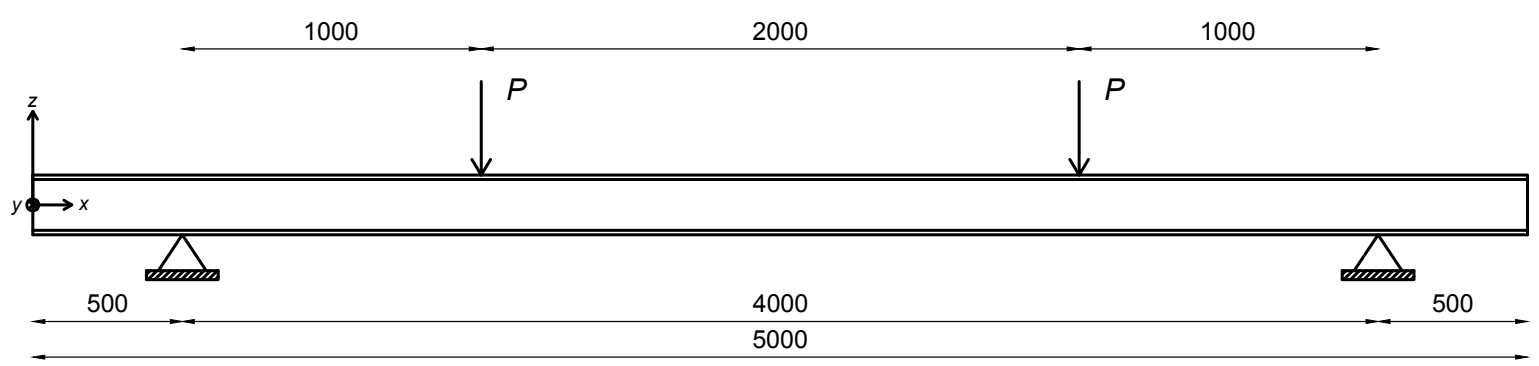

Figure 6: Schematic representation of the progressive damage test - front view (dimensions in $\mathrm{mm}$ ). The load that is applied by each hydraulic jack is indicated as $P$.

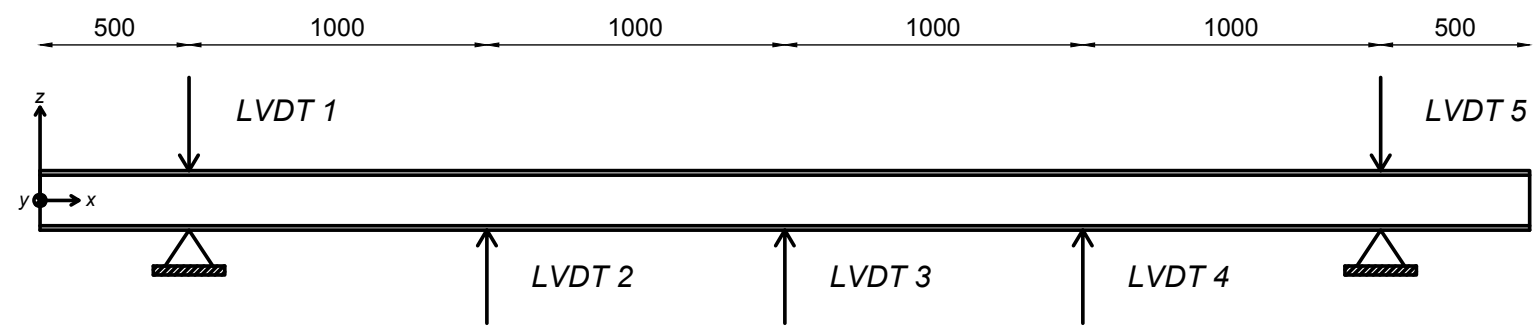

Figure 7: Locations where the five LVDTs are measuring the vertical displacements of the beam during quasi-static loading and unloading (distances in $\mathrm{mm}$ ).

cycle, up to the failure of the beam, are not shown as only the LVDT in the middle of the beam was measuring for this cycle. The other LVDTs were detached to avoid damaging them during the further loading and failure of the beam. The maximum deflections at the center of the beam, including the last loading cycle, are displayed in Fig. 10b. The slope of the load-deflection curve changes after the second loading cycle (loading cycle amplitude of $60 \mathrm{kN}$ ), when the beam exceeded its cracking load, which was measured at $2 \mathrm{P} \approx 50 \mathrm{kN}$ and calculated at $2 \mathrm{P} \approx 45 \mathrm{kN}$, with the assumption of a tensile strength of $f_{c t}=5 \mathrm{MPa}$ for the C70/85 concrete (Fig. 6). The observed crack pattern, up to the failure of the beam, is displayed in Fig. 11.

\subsection{Modal tests}

Before starting the progressive damage test and after each unloading phase, the beam was repeatedly subjected to dynamic strain tests so as to identify its modal characteristics, i.e., natural frequencies and strain mode shapes. These tests were performed for a range of ambient temperatures. In the present section, the modal tests themselves are described. The experimental setup for changing the ambient temperature will be described next, in Section 3.4.

Roller supports used for quasi-static laboratory testing of beams, such as the one that is displayed in Fig. 5a, may not at all behave as a roller support anymore during dynamic testing, and important dynamic interaction between the beam and the supporting structure may occur [19]. In order to avoid this, the beam is lifted from the roller supports before starting a series of modal tests. Tires are placed below the beam at both ends and when they are inflated, the beam is detached from the static roller supports and rests solely on the flexible tires (Fig. 12). The inflated tires are very flexible and they act as vibration isolators, such that the beam has dynamically de- 


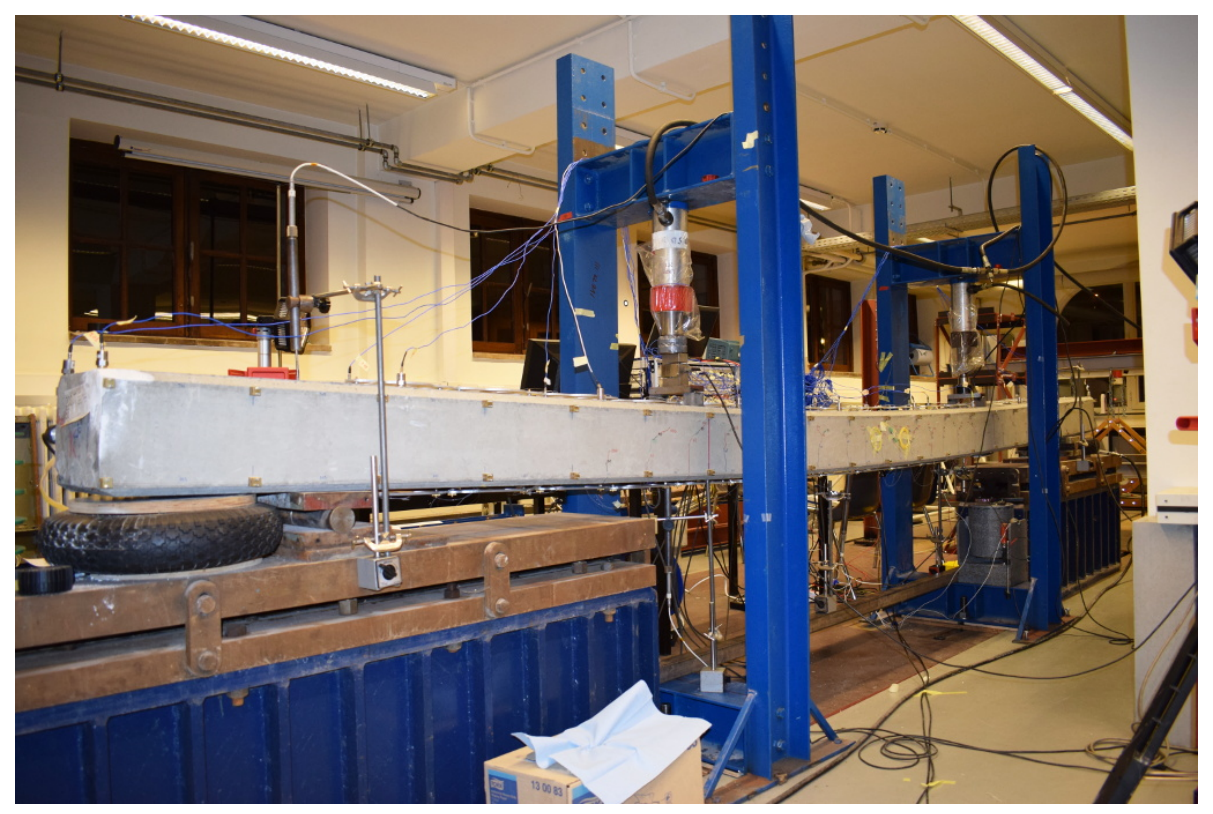

Figure 8: The prestressed concrete beam during a four-point bending test as part of the progressive damage testing. The deflection of the beam under static loading by the hydraulic jacks is clearly visible. The tires are deflated during the static tests and therefore they are not touching the beam.

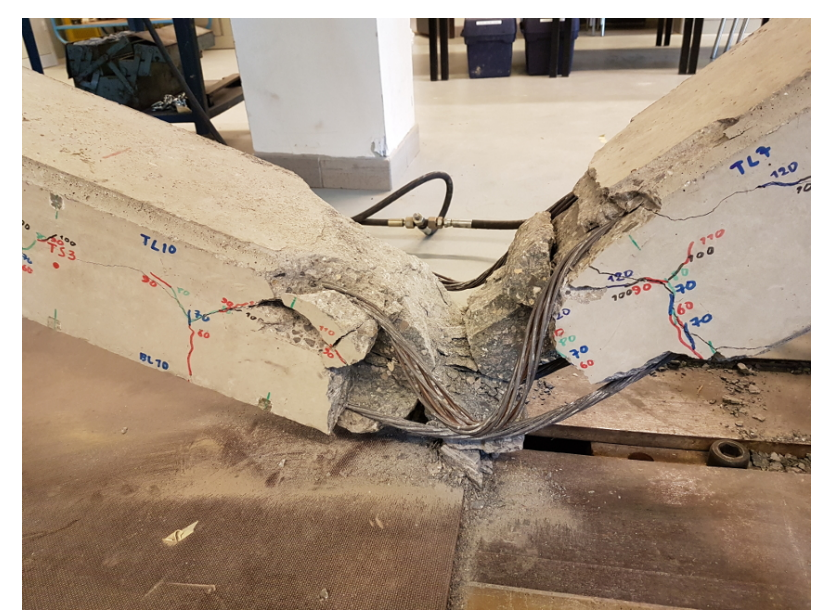

Figure 9: The beam after failure.

coupled (free-free) boundary conditions. The assumption of dynamic free-free boundary conditions is confirmed when the identified natural frequency of the highest rigid-body mode of the beam $(\approx$ $16 \mathrm{~Hz})$ is compared with the identified natural frequency of the lowest vibration mode of the beam $(\approx 36 \mathrm{~Hz})$. The difference is sufficient to consider the beam dynamically isolated from the rest of the laboratory.

The beam is excited by a Gaussian white noise force signal, which is generated by a Tektronix AFG 3022B signal generator in the frequency bandwidth (0-400) Hz. The signal is applied in the vertical direction by an MB Dynamics Modal 50A electrodynamic shaker that is connected with the beam at a single location, at $3.5 \mathrm{~m}$ from its left end (Fig. 13). The duration of every modal 


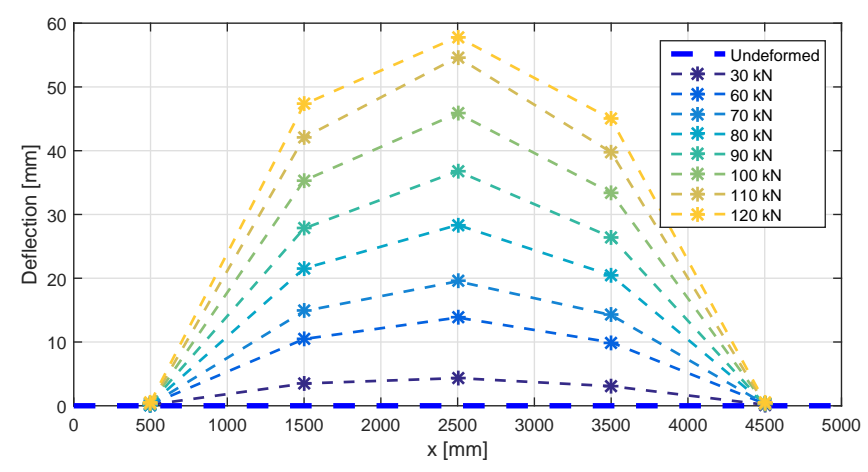

(a)

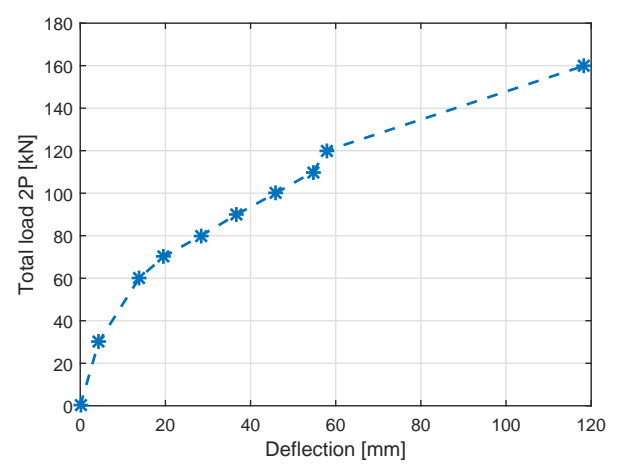

(b)

Figure 10: Deflection of the beam during progressive damage testing: (a) maximum deflections during each of the first eight loading cycles. The measuring points, indicated with an asterisk, correspond to the locations of the 5 LVDTs; (b) Load-deflection curve for all loading cycles as measured at midspan using LVDT 3.

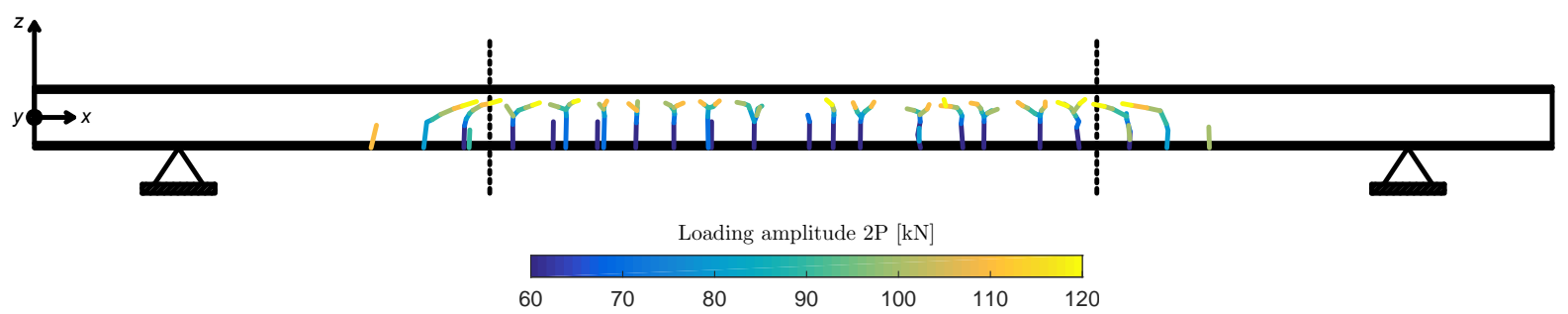

Figure 11: The crack pattern of the beam, as observed for the different loading cycles. The dashed lines indicate the locations of the hydraulic jacks.

test is $70 \mathrm{~s}$. The number of modal tests and the temperature range that was achieved for each damage state are summarized in Table 1.

\begin{tabular}{cccc} 
State & Amount of tests & Temp. range $\left(\mathbf{T}_{\min }-\mathbf{T}_{\max }\right)\left[{ }^{\circ} \mathbf{C}\right]$ & $\mathbf{T}_{\max }-\mathbf{T}_{\min }\left[{ }^{\circ} \mathbf{C}\right]$ \\
\hline \hline Undamaged & 161 & $22.0-32.6$ & 10.6 \\
\hline After $30 \mathrm{kN}$ & 144 & $21.6-34.5$ & 12.9 \\
\hline After $60 \mathrm{kN}$ & 166 & $18.3-34.3$ & 16.0 \\
\hline After $70 \mathrm{kN}$ & 126 & $19.4-34.3$ & 14.9 \\
\hline After $80 \mathrm{kN}$ & 107 & $22.3-34.5$ & 12.2 \\
\hline After $90 \mathrm{kN}$ & 115 & $23.6-34.6$ & 11.0 \\
\hline After $100 \mathrm{kN}$ & 109 & $23.3-34.5$ & 11.2 \\
\hline After $110 \mathrm{kN}$ & 139 & $22.9-34.3$ & 11.4 \\
\hline After $120 \mathrm{kN}$ & 112 & $22.0-34.6$ & 12.6 \\
\hline
\end{tabular}

Table 1: Number of modal tests that have been performed for each damage state after unloading, and the related temperature range.

Dynamic strains are measured with four chains of multiplexed optic fiber Bragg grating strain sensors from FBGS. Each chain contains 20 FBG sensors. The chains are attached to the side of the top and the bottom edges of the beam along its longitudinal direction through a custom clamping 


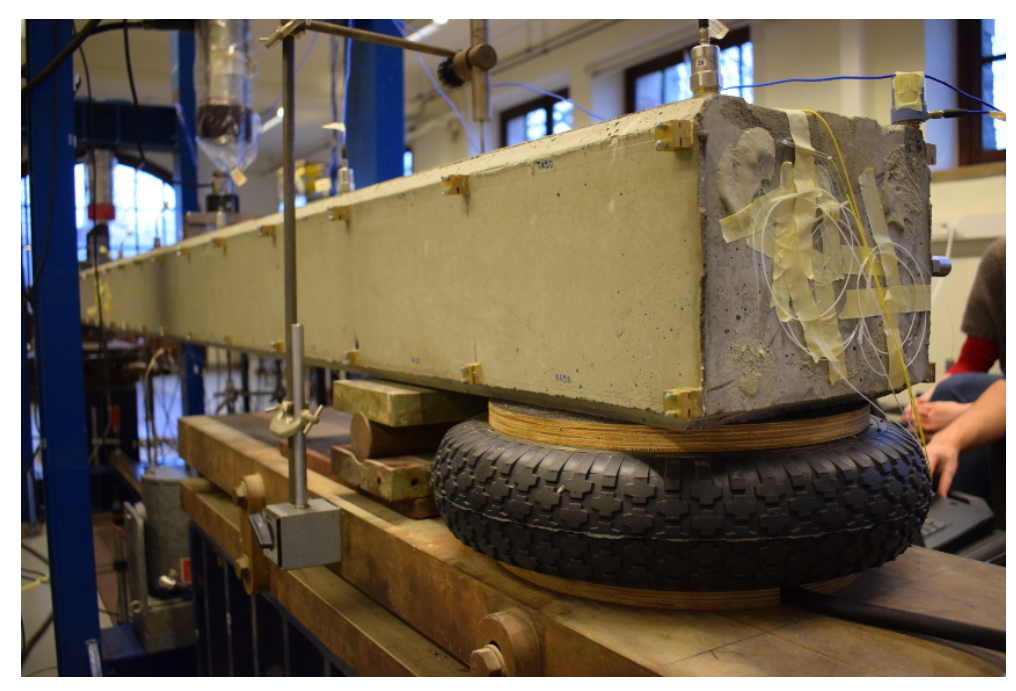

Figure 12: One of the inflated tires used to approximate dynamic free-free boundary conditions.

system that was introduced in [19]. This clamping system allows for point connections between an optic fiber and the test structure, such that the macro-strain between both point connections can be measured when an FBG sensor is situated in between (Fig. 13). Fig. 14 displays a single clamping block. The bottom part or "base" of the clamping block is directly glued onto the beam, while the top part is screwed onto the bottom part, clamping the fiber that is situated in between both parts. In the present tests, the distance between two consecutive clamping blocks is $25 \mathrm{~cm}$. There is one FBG sensor in between any two clamping blocks, resulting in a quasi-distributed macro-strain measurement along the length of the beam. If the FBG sensors would be directly glued onto the beam, they would measure local strains instead of macro-strains. As discussed in Section 2.1, the precise interpretation of local strains is much harder than that of macro-strains, as local strains depend heavily on their precise position with respect to possible cracks. The optic fibers are prestrained to ensure that they always remain in tension during the dynamic tests. Since FBGs are sensitive to both strain and temperature, the fibers are covered with thermal insulation, to ensure that temperature fluctuations in the laboratory would not affect the measurements.

For the interrogation of the Bragg gratings, the ability to determine the Bragg wavelength shift with adequate accuracy and precision is essential. Therefore, the strain acquisition system is an interrogator of relatively high wavelength accuracy $( \pm 1 \mathrm{pm})$ and precision $(<0.1 \mathrm{pm})$, the FAZ Technologies FAZT-I4. The accuracy is defined as the proximity of the measurements to the actual values while the precision is defined as the degree to which repeated measurements under unchanged conditions show the same results [29]. The FAZT-I4 has four channels that are simultaneously scanned by a tunable laser source, offering the simultaneous interrogating of four FBG fibers with a maximum of 30 FBGs per fiber. The sampling frequency of the FAZT-I4 is $\mathrm{f}_{\mathrm{s}}$ $=1000 \mathrm{~Hz}$.

The force level of the shaker is chosen in such a way that the position-averaged root mean square (RMS) value of the measured strains is about $0.04 \mu \epsilon$, which is similar to the strain levels that stiff civil structures, like stiff bridges, would exhibit during ambient or operational excitation. 


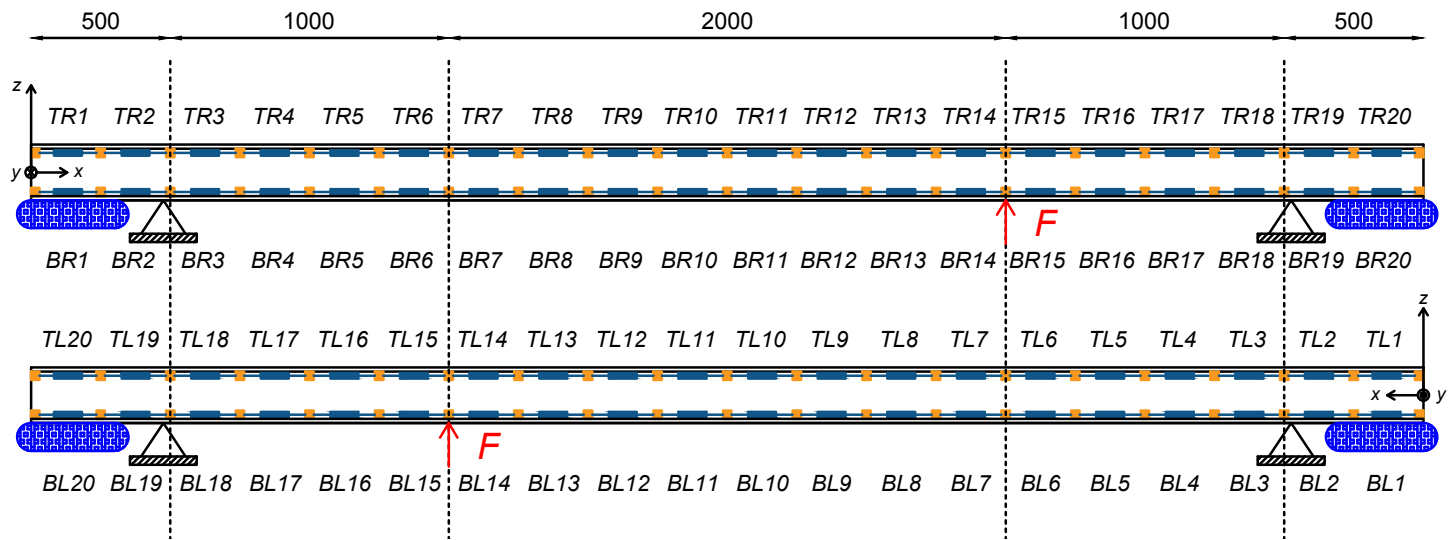

Figure 13: Left-right and right-left front view of the beam, with a schematic representation of the attachment of the four optical fibers. The yellow rectangles represent the clamping blocks. The blue rectangles represent the FBG senors in between the clamping blocks. All FBG sensors are labeled; TR stands for top tight, BR for bottom right, TL for top left and BL for bottom left side of the beam. The dynamic force that is applied by the shaker to the beam is indicated by $F$. Dimensions in $[\mathrm{mm}]$.

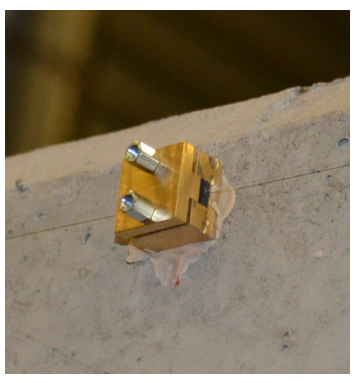

(a)

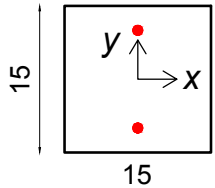

Top view

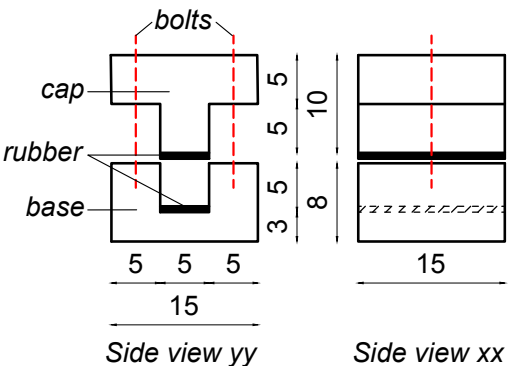

Side view $x x$

(b)

Figure 14: Clamping system for the point-wise attachment of optic fibers to a structure: (a) photo of a mounted clamping block and glass fiber, (b) blueprints of a clamping block (dimensions in [mm])

\subsection{Temperature influence tests}

The influence of temperature changes on the modal characteristics of the beam is investigated. A temperature range of at least $10^{\circ} \mathrm{C}$ is aimed at. To this end, the beam is covered with a tent structure, as shown in Fig. 15. Six portable $2 \mathrm{~kW}$ floor fan heaters are used to increase the temperature in the tent. The fan heaters are uniformly distributed in the tent to create uniform temperature conditions, as shown in Fig. 16.

The temperature is measured with thermocouples at seven locations. Two sensors are measuring the temperature inside the core of the beam, three on the surface of the beam and two are measuring the air temperature inside the tent (Fig. 17). The sensor layout is schematically represented in Fig. 18. The thermocouples are connected to a National Instruments NI-9213 C series temperature module and they are continuously sampled at a frequency of $1 \mathrm{~Hz}$. The concrete core temperature is measured at the locations where the static supports are applied during the PDT. In this way, the holes that have been made to reach the core with the thermocouples do not influence the crack formation during the PDT.

The maximum temperature that can be achieved with this setup is about $35^{\circ} \mathrm{C}$. The temperature influence test consists of two phases: a heating up phase during which the fan heaters are 


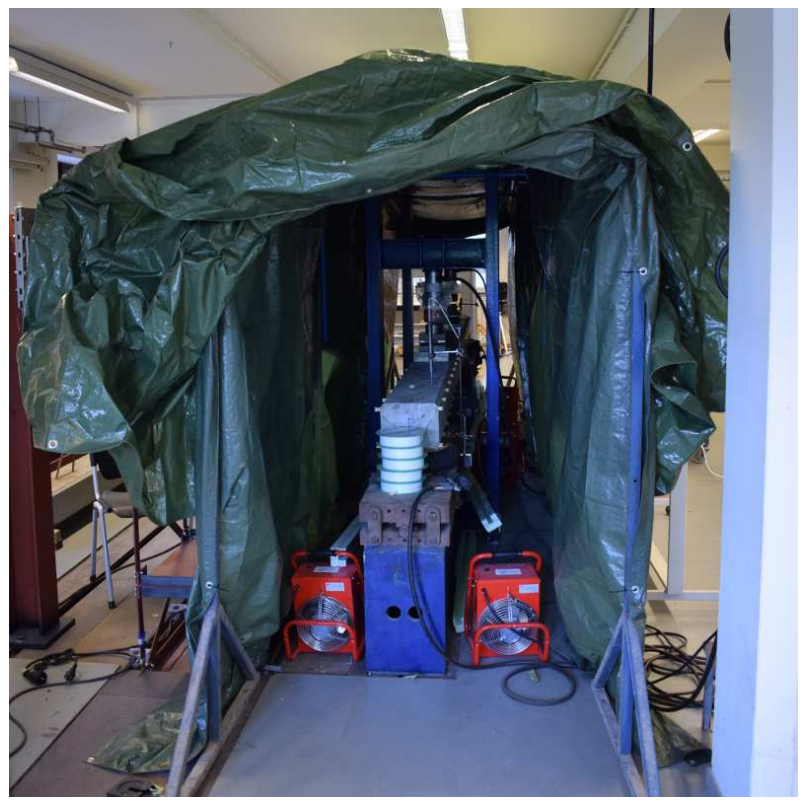

Figure 15: Temperature influence test setup. The tent was completely closed during the tests and opened only for taking the photograph. Two fan heaters are visible on the floor, next to the beam.

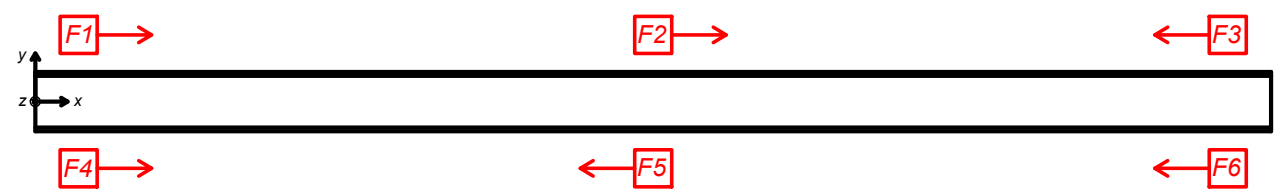

Figure 16: The setup of the floor fan heaters (top view). The arrows indicate the direction in which the fans are blowing the hot air.

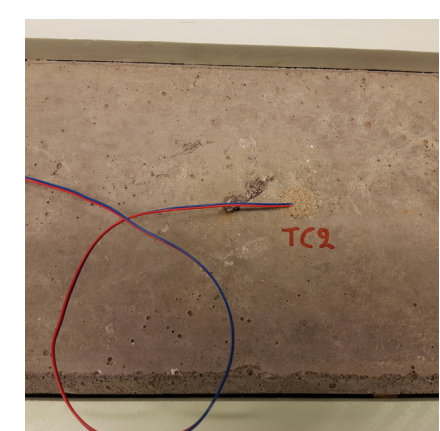

(a)

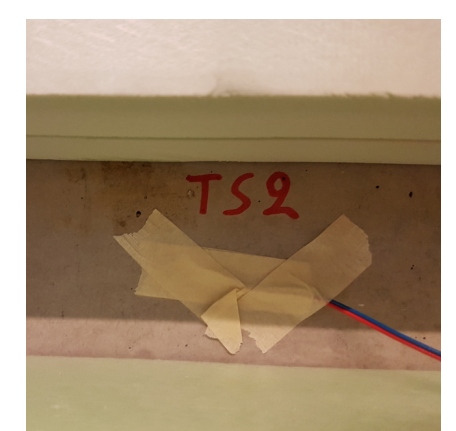

(b)

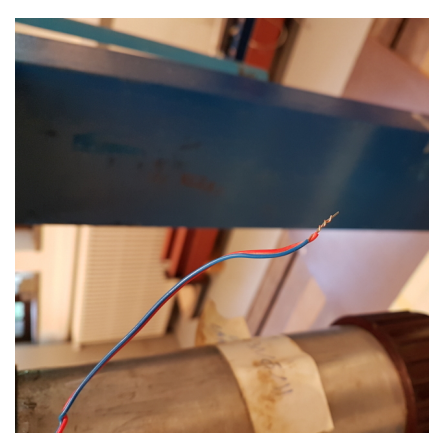

(c)

Figure 17: Thermocouples measuring the temperature (a) in the core of the beam, (b) on the surface of the beam and (c) in the air inside the tent.

switched on, and a cooling down phase during which they are switched off. The heating up phase, from room temperature to about $35^{\circ} \mathrm{C}$, lasts for about $24 \mathrm{~h}$. The cooling down phase from $35^{\circ} \mathrm{C}$ to room temperature lasts from a minimum of $48 \mathrm{~h}$ to a maximum of $90 \mathrm{~h}$, depending on the room temperature outside the tent. Every half an hour, a modal test is performed, as described in 
Section 3.3. The temperature distribution inside the beam is considered uniform when the absolute difference between any of the thermocouples that are measuring the core or surface temperature of the beam is smaller than $1^{\circ} \mathrm{C}$. Regardless of the temperature distribution inside the beam, the nominal beam temperature is computed as the average of the values measured by these five thermocouples. The air temperature is changing much more rapidly than the beam temperature and the two are in agreement only at steady-state room temperature. Thus, the air temperature is discarded in the further analysis. The precise locations at which thermocouples measure the surface or core temperature of the beam, are listed in Table 2.

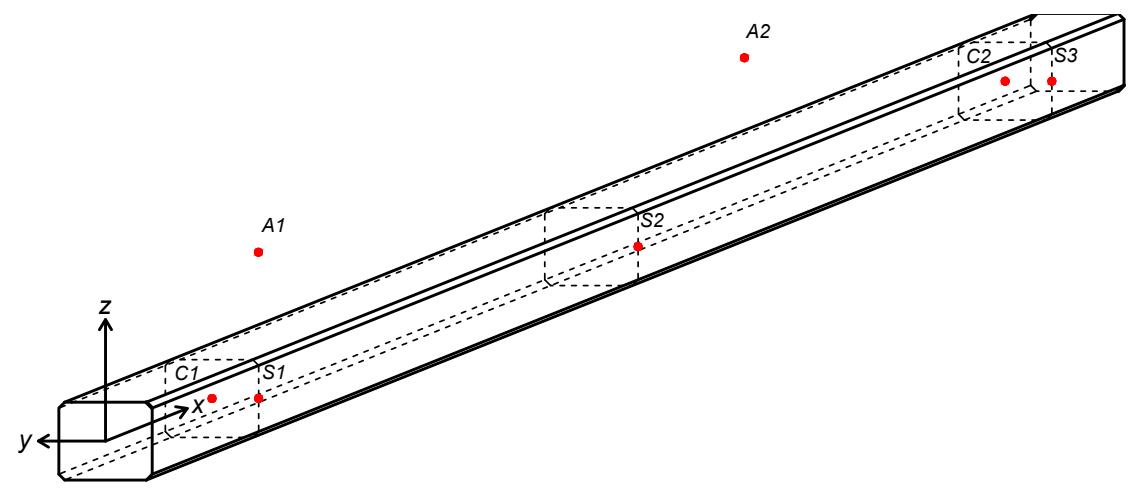

Figure 18: The setup of the thermocouples. S1-S3 are the surface sensors, C1, C2 are the core sensors and A1, A2 are the air sensors.

\begin{tabular}{cccc} 
Thermocouple & $\mathbf{x}[\mathbf{m m}]$ & $\mathbf{y}[\mathbf{m m}]$ & $\mathbf{z}[\mathbf{m m}]$ \\
\hline \hline C1 & 250 & 0 & 0 \\
\hline C2 & 4750 & 0 & 0 \\
\hline S1 & 250 & -100 & 0 \\
\hline S2 & 2500 & -100 & 0 \\
\hline S3 & 4750 & -100 & 0 \\
\hline
\end{tabular}

Table 2: Locations of the thermocouples that measure the temperature in the core $(\mathrm{C})$ or at the surface $(\mathrm{S})$ of the beam, in terms of the coordinate system of Fig. 18.

A typical heating up/cooling down temperature time history, as recorded from all seven thermocouples, is displayed in Fig. 19. The test starts at a steady-state room temperature of about $22^{\circ} \mathrm{C}$. All the heating units are simultaneously switched on two hours after the beginning of the measurements. The beam reaches its maximum temperature of $34.5^{\circ} \mathrm{C}$ after about 26 hours. During this period, the air temperature is consistently higher than the core and the surface temperature. The fluctuations of the air temperature between $35^{\circ} \mathrm{C}$ and $39^{\circ} \mathrm{C}$ are due to the safety thermostats of the fan heaters. After they reach the maximum temperature defined by their thermostats, the heaters are automatically switching off. They are switching on again when the temperature drops below $35^{\circ} \mathrm{C}$. The cooling down period starts after 30 hours of measurements, by permanently switching off all the heaters. The cooling down lasts for 90 hours, as the lowest possible temperature is desired. To facilitate the process, the laboratory is ventilated during a cool day, at the end of the measurements. The lowest temperature of $18.3^{\circ} \mathrm{C}$ is achieved during this day. 


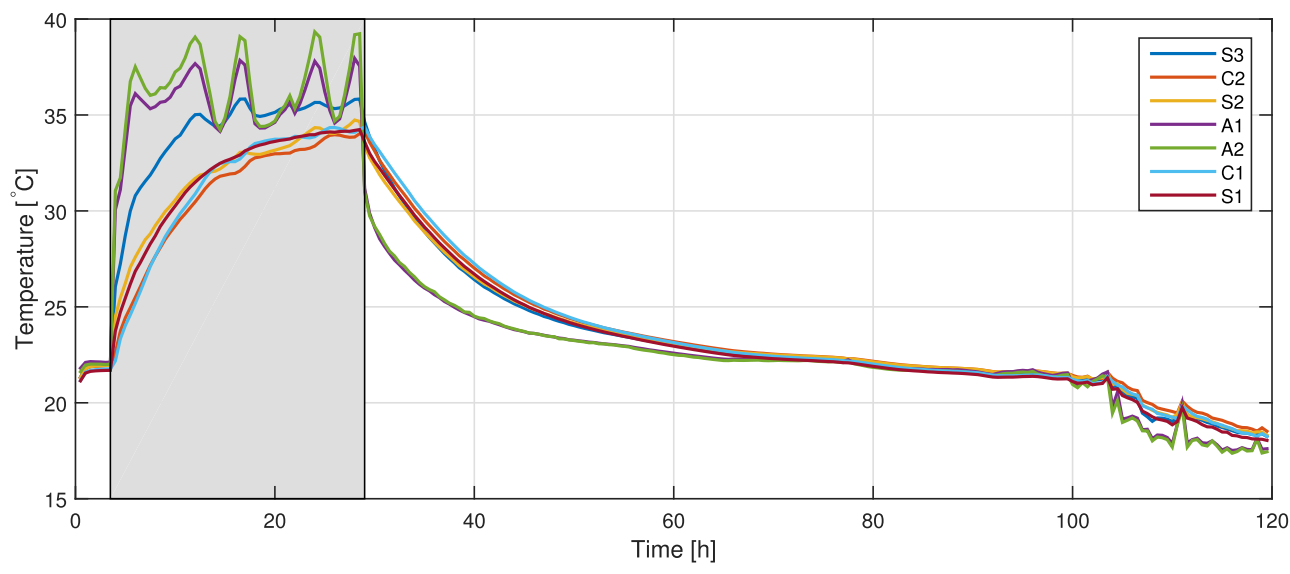

Figure 19: Typical heating up/cooling down temperature time history. The shaded part of the graph indicates the time range during which the temperature distribution in the beam is considered non-uniform.

\section{Experimental results}

Dynamic strain data obtained from the FBG sensors are used for identifying the modal characteristics of the beam. Although the force that is exerted by the shaker can also be measured, only the measured dynamic strains are used in the system identification, in order to simulate insitu conditions. The resulting output-only or operational modal analysis is conducted with the Matlab toolbox MACEC [30]. First, the static or DC offset is removed from all measured strain signals. Then, a fourth-order Butterworth filter with a high-pass frequency of $4 \mathrm{~Hz}$ is applied to all channels, in order to remove the influence of small temperature fluctuations on the strain measurements during the modal tests. Subsequently, the output-only, data-driven stochastic subspace identification (SSI-data) method [31] is employed for identifying a range of state-space models from the strain data. The following parameter choices are made: the model order ranges from 2 to 100 in steps of 2, and the half number of Hankel block rows is 40 . The modal characteristics that are computed from the state-space models are employed for constructing stabilization diagrams [32]. Four vertical bending modes below $400 \mathrm{~Hz}$ are manually selected from this diagram.

\subsection{Influence of damage versus temperature on natural frequencies}

The evolution of the natural frequencies of the first two bending modes (B1 and B2) throughout the progressive damage test is displayed in Fig. 20. The presented values were obtained at a uniform beam temperature of $24^{\circ} \mathrm{C}$. The natural frequencies gradually decrease with increasing level of damage. The relative reduction of the natural frequency values is about $3.5 \%$ for modes B1 and B2, when the undamaged beam natural frequencies are compared with the natural frequencies after the $8^{\text {th }}$ loading cycle (loading amplitude of $120 \mathrm{kN}$ ). Similar results are obtained for the third and fourth bending modes (B3 and B4) and therefore they are not reproduced here.

In order to investigate the influence of temperature versus damage on the natural frequencies of the vertical bending modes of the beam, the identified natural frequencies of modes B1 and B2 are plotted as a function of temperature in Fig. 21. The natural frequencies that are obtained from modal tests with uniform beam temperature are shown (Fig. 19), while the ones from tests with non-uniform temperature are excluded since the difference between the core and the surface temperature hinders their classification at a specific temperature. For each loading cycle (i.e., each 

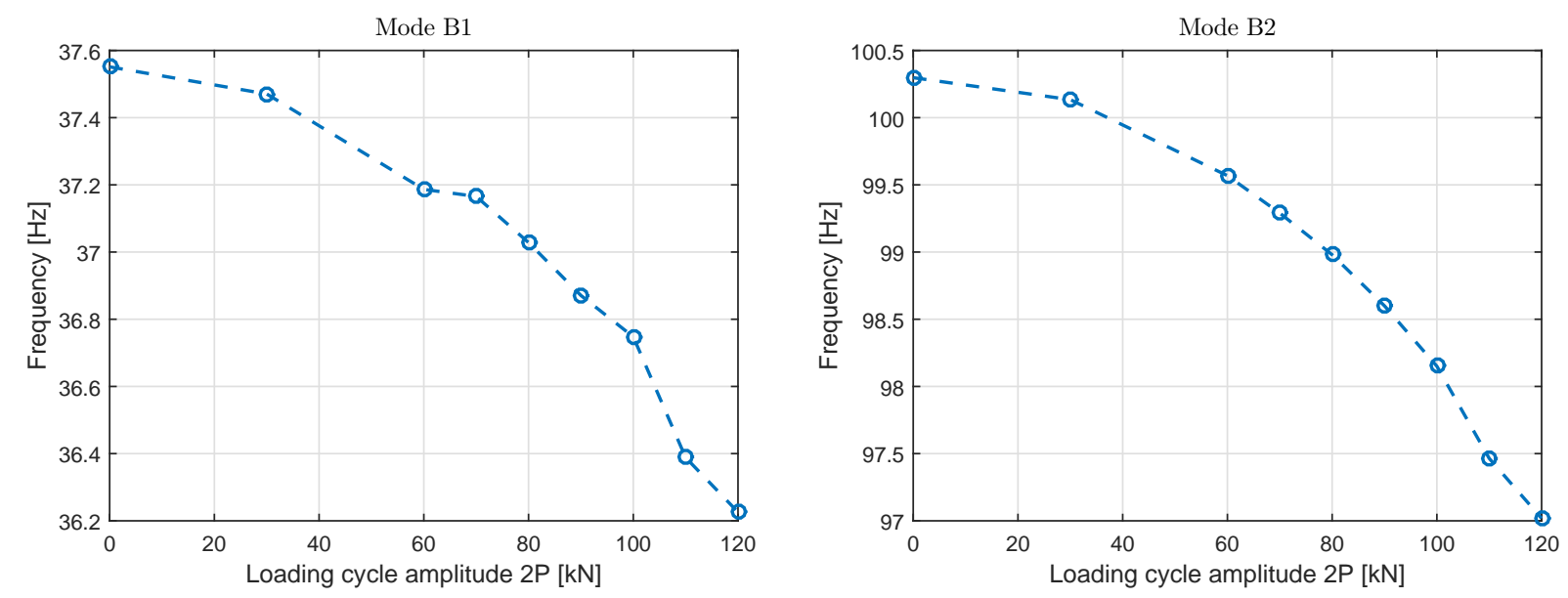

Figure 20: Evolution of the natural frequencies of the prestressed concrete beam at the different stages of the progressive damage test, as identified from dynamic strains, for the first two bending modes and at a uniform beam temperature of $24^{\circ} \mathrm{C}$. The $0 \mathrm{kN}$ loading cycle amplitude corresponds to the undamaged beam.

damage stage), a straight line is fitted through the corresponding temperature-natural frequency data. Since the available temperature range is between $10^{\circ} \mathrm{C}$ and $15^{\circ} \mathrm{C}$ for each loading step, a clear, linear trend between natural frequency and temperature can be observed. An increase of $\Delta \mathrm{T}=10^{\circ} \mathrm{C}$ in temperature results in a relative decrease of about $\Delta \mathrm{f}=0.8 \%$ for both natural frequencies, which translates to a change of about $\Delta E=0.8 \mathrm{GPa}$ for the dynamic Young's modulus. The relationship appears to be relatively consistent among both modes and among the different damaged states. Similar results are obtained for the third and fourth bending modes (B3 and B4) and therefore they are not reproduced here.

The influence of temperature on the natural frequencies of the beam is quite large when compared to this of damage, given that a change of temperature by $40^{\circ} \mathrm{C}$ can create a change in the natural frequency values of $3.5 \%$, the same as the one due to damage. This confirms the conclusions of several researches $[6,9,14,15]$ that the use of natural frequencies for SHM purposes in civil structures requires data normalization, so as to filter out the temperature influence. Hence, it would be of significant importance for SHM if a modal characteristic could be identified that is less sensitive to temperature changes and more sensitive to damage.

\subsection{Influence of damage versus temperature on strain mode shapes}

The strain mode shapes $\phi_{t}$ that have been identified in an output-only test $t$ are usually normalized such that one of the strain mode shape components equals unity [31]. A different normalization scheme [33] is applied here, which allows for a more direct comparison of the strain mode shapes that have been determined at different loading cycles and temperatures. It consists of two normalization steps: first rotating $\phi_{t}$ such that one of its components $\phi_{t, l}$ has zero imaginary part and second re-scaling $\phi_{t}$ such that its Euclidean norm has unit length. Application of the first step yields:

$$
\phi_{1 t}=\phi_{t} e^{-i \alpha_{t, l}}
$$



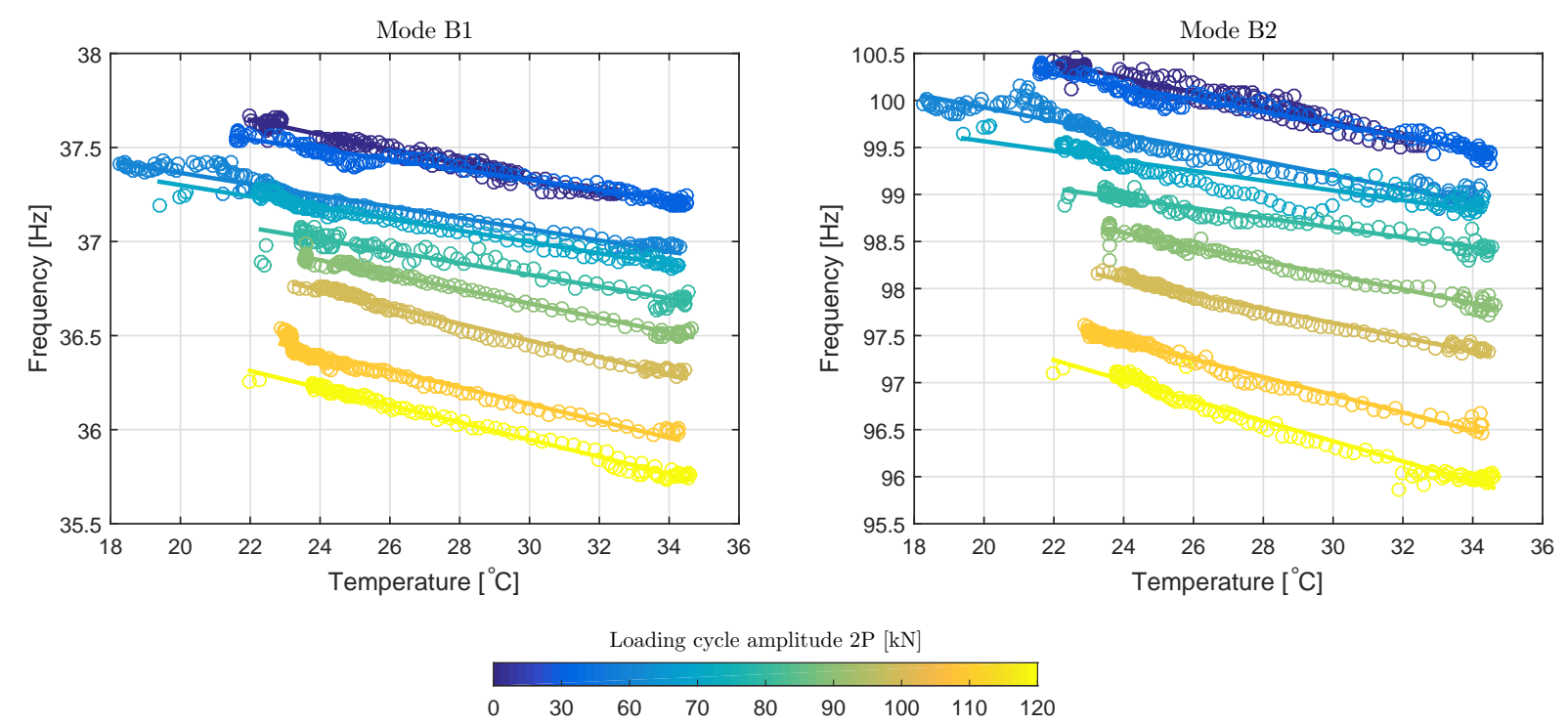

Figure 21: Evolution of the natural frequencies of the prestressed concrete beam as a function of temperature for the first two vertical bending modes and for the first 8 loading cycles of the progressive damage test. The $0 \mathrm{kN}$ loading cycle amplitude corresponds to the undamaged beam.

where $\alpha_{t, l}$ is the phase angle of $\phi_{t, l}$. Application of the second step results in:

$$
\phi_{2 t}=\frac{\phi_{1 t}}{\left\|\phi_{1 t}\right\|}
$$

The influence of the temperature fluctuations throughout the PDT on the strain mode shapes is investigated. The strain mode shapes obtained from all modal tests are used, regardless of the temperature distribution inside the beam (Fig. 19). The average temperature between the thermocouples is considered as the nominal beam temperature for each test. First, for each damage state (or PDT step), the strain mode shapes are clustered in temperature groups that each have a non-overlapping range of $2^{\circ} \mathrm{C}$. Then, for each temperature group $j$, the sample mean $\mu\left[\phi_{2}^{(j)}\right]$ of all strain mode shapes in the group is computed, as well as the sample standard deviation $\sigma\left[\phi_{2}^{(j)}\right]$ and the related $\pm 2 \sigma$ confidence interval $\mathrm{CI}\left[\phi_{2}^{(j)}\right]$, which boils down to a $95 \%$ confidence interval when the samples are normally distributed:

$$
\begin{aligned}
\mu\left[\phi_{2}^{(j)}\right] & =\frac{1}{n_{\mathrm{s}}} \sum_{s=1}^{n_{\mathrm{s}}} \phi_{2, s}^{(j)} \\
\sigma\left[\phi_{2}^{(j)}\right] & =\sqrt{\frac{1}{n_{\mathrm{s}}} \sum_{s=1}^{n_{\mathrm{s}}}\left(\phi_{2, s}^{(j)}-\mu\left[\phi_{2}^{(j)}\right]\right)^{2}} \\
\mathrm{CI}\left[\phi_{2}^{j}\right] & =\left[-2 \sigma\left[\phi_{2}^{(j)}\right], 2 \sigma\left[\phi_{2}^{(j)}\right]\right]
\end{aligned}
$$

where $n_{\mathrm{S}}$ denotes the number of modal tests within the temperature group $j$ and $\phi_{2, s}^{(j)}$ is the strain mode shape of a mode identified from test $s$. 
The mean strain mode shapes of the different temperature groups of modes B1, B2 and B3 are displayed in Figures 22a-c, for the second loading cycle (loading amplitude of $60 \mathrm{kN}$ ), where the largest temperature range is recorded (Table 1). Similar results are obtained for the fourth bending mode (B4) and therefore they are not reproduced here. In addition to the mean values, also the $95 \%$ confidence intervals are provided. In Fig. $22 \mathrm{~d}$, the zone between the points where the load is applied (1500-3500 mm) is displayed in detail for mode B1. It can be clearly observed that the confidence intervals for the different temperature groups overlap completely, and they all heave nearly the same width. It can therefore be concluded that, in the present experiment, there is no clear influence of the temperature on the strain mode shapes, for the given temperature range of $16^{\circ} \mathrm{C}$.

In a next step, the influence of the progressively applied damage on the strain mode shapes is investigated. Since the temperature does not influence the strain mode shapes, all vibration tests (i.e., for all temperature values) performed after a given load cycle are considered together. In Figures 23a-c, the sample mean of the complete set of strain mode shapes $\mu\left[\phi_{2}\right]$ that are obtained at a given damage state are plotted, together with the $95 \%$ confidence interval of that set $\left(\mathrm{CI}\left[\phi_{2}\right]=\right.$ $\left.\left[-2 \sigma\left[\phi_{2}\right], 2 \sigma\left[\phi_{2}\right]\right]\right)$. In Fig. $23 \mathrm{~d}$, the zone between the points where the load is applied (1500$3500 \mathrm{~mm}$ ), which is the zone where the maximum stresses appear in a four-point bending test, is displayed in detail for mode B1. The influence of the progressive damage on the strain mode shapes is clearly larger than the statistical uncertainty of the identified strain mode shapes. Similar results are obtained for the fourth bending mode (B4) and therefore they are not reproduced here.

It has been demonstrated above that temperature does not influence the strain mode shapes, therefore, this statistical uncertainty must relate to other causes of variability in the strain mode shapes at a given damage state, in particular identification errors. The fact that the confidence intervals in Fig. 22d all fall on top of each other, indicates that the identification errors have low bias. This implies that the uncertainty on the identified strain mode shapes can be reduced by averaging. Indeed, the standard deviation of the sample mean of the entire set of $N_{\mathrm{s}}$ samples (i.e., identified strain mode shapes) obtained at a given damage state is related to the standard deviation of the set as:

$$
\sigma\left[\mu\left[\phi_{2}\right]\right]=\frac{\sigma\left[\phi_{2}\right]}{\sqrt{N_{\mathrm{s}}}}
$$

and the related $95 \%$ confidence interval reads

$$
\mathrm{CI}\left[\mu\left[\phi_{2}\right]\right]=\left[-2 \sigma\left[\mu\left[\phi_{2}\right]\right], 2 \sigma\left[\mu\left[\phi_{2}\right]\right]\right]
$$

Fig. 24 displays, for the first bending mode, the sample mean of the complete set all repeatedly identified strain mode shapes $\mu\left[\phi_{2}\right]$ that are obtained at a given damage state, together with the $95 \%$ confidence interval of the sample mean of each set. Note that the sample mean values of Figs. 23a,d and Figs. 24a,b are identical, but that the width of the confidence intervals in Figs. 24a,b are a factor $1 / \sqrt{N_{\mathrm{s}}}$ narrower than in Figs. 23a,d, because in Figs. 24a,b the uncertainty of the averaged, sample mean values is considered. Thanks to the averaging of identification errors in repeated modal tests, the influence of the concrete cracking on the modal strains can be even more clearly observed, especially at early stages of damage (low load cycle amplitudes). Similar accuracy is obtained for modes B2, B3 and B4 and thus these results are not reproduced here.

It must be remembered that, due to the fact that the beam has very low self weight when compared to the loading and the fact that the modal tests are performed in unloaded condition, 

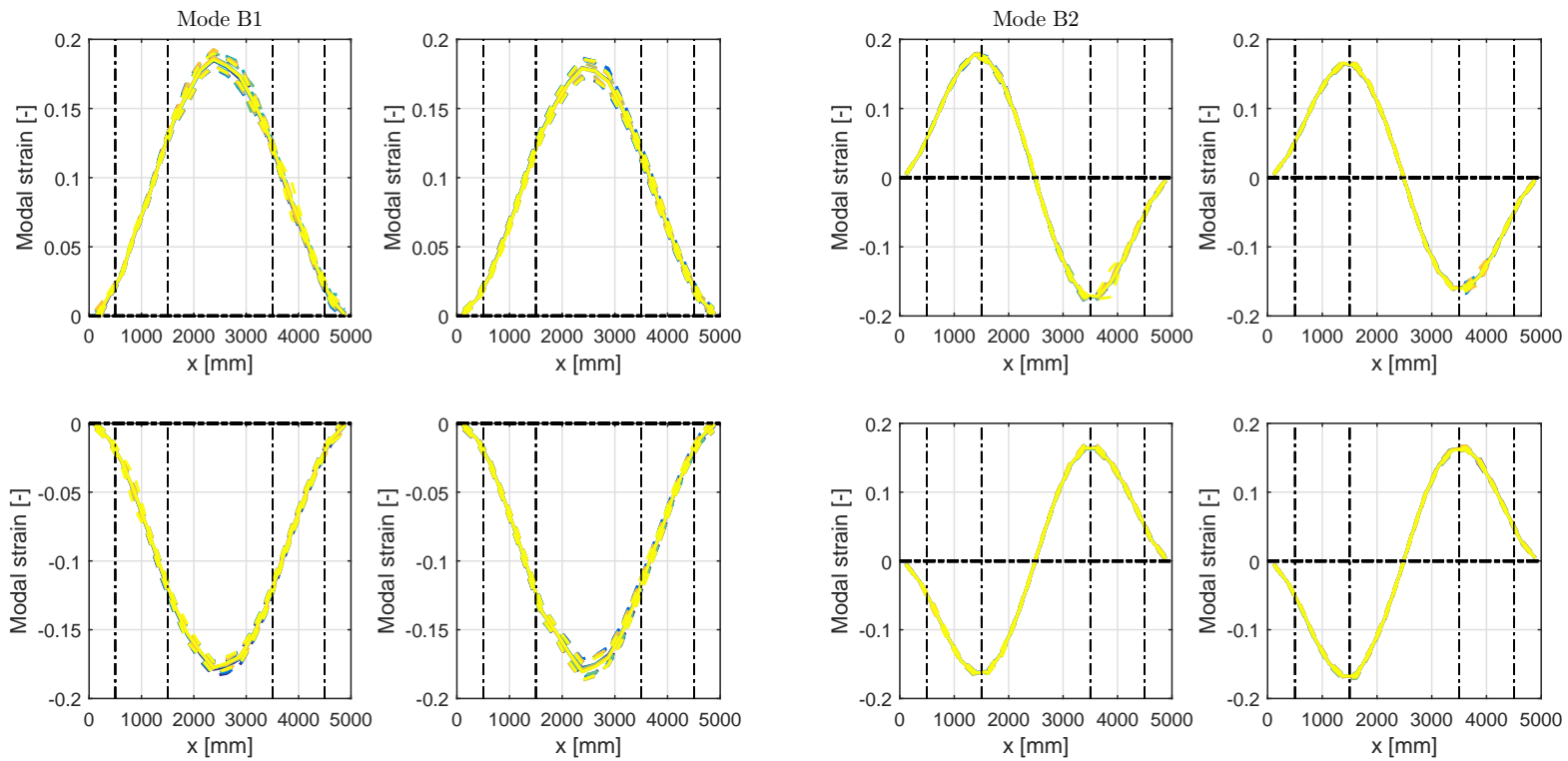

(a)

(b)
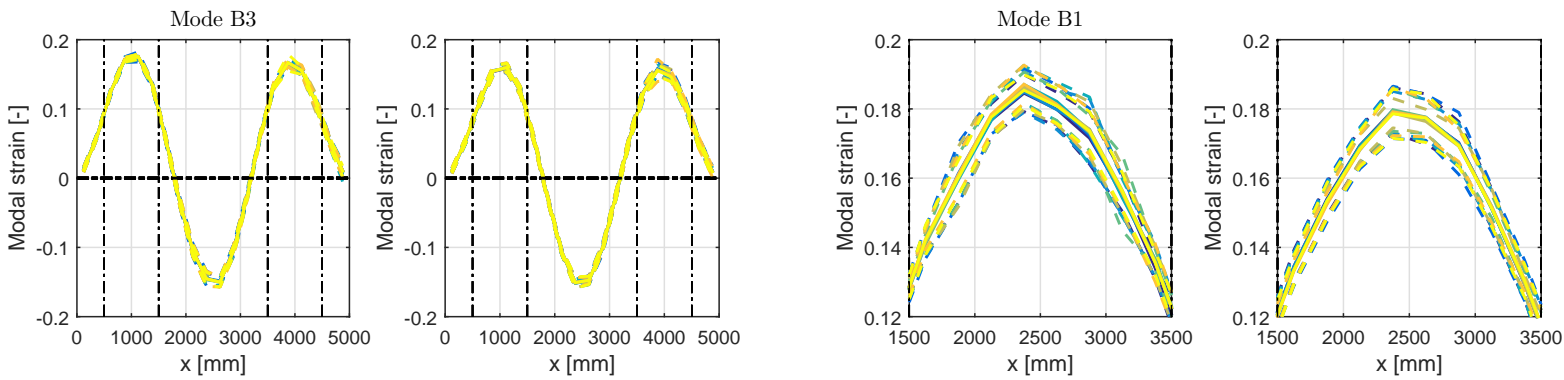

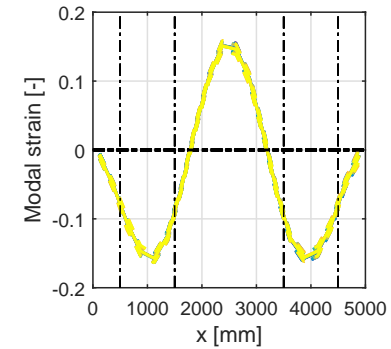

(c)

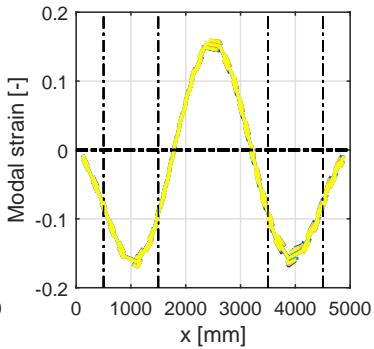

(d)
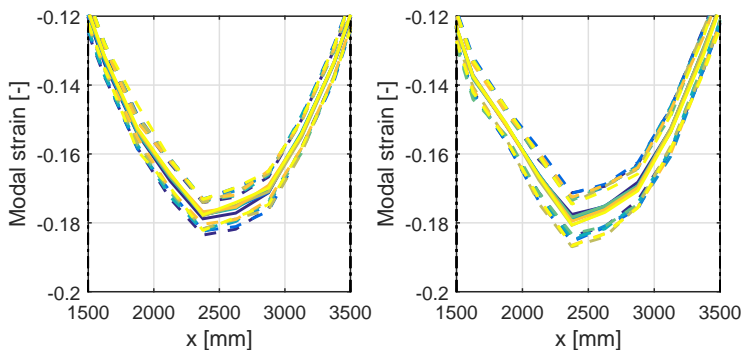

Group temperature $\left[{ }^{\circ} \mathrm{C}\right]$

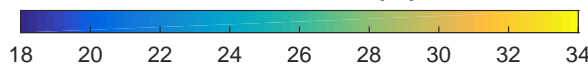

Figure 22: Sample mean $\mu\left[\phi_{2}^{(j)}\right]$ and $95 \%$ confidence interval $\mathrm{CI}\left[\phi_{2}^{(j)}\right]$ of the strain mode shapes that have been identified in each temperature group $j$, after the $2^{\text {nd }}$ loading cycle $(60 \mathrm{kN}$ ): (a) first, (b) second, and (c) third bending mode, and (d) zoom of the first bending mode. The top and bottom subplots contain the strains at the top and bottom sides of the beam (as defined in Fig. 13), respectively. The left and right subplots contain the strains at the sides of the beam with positive and negative y-coordinates, respectively. 

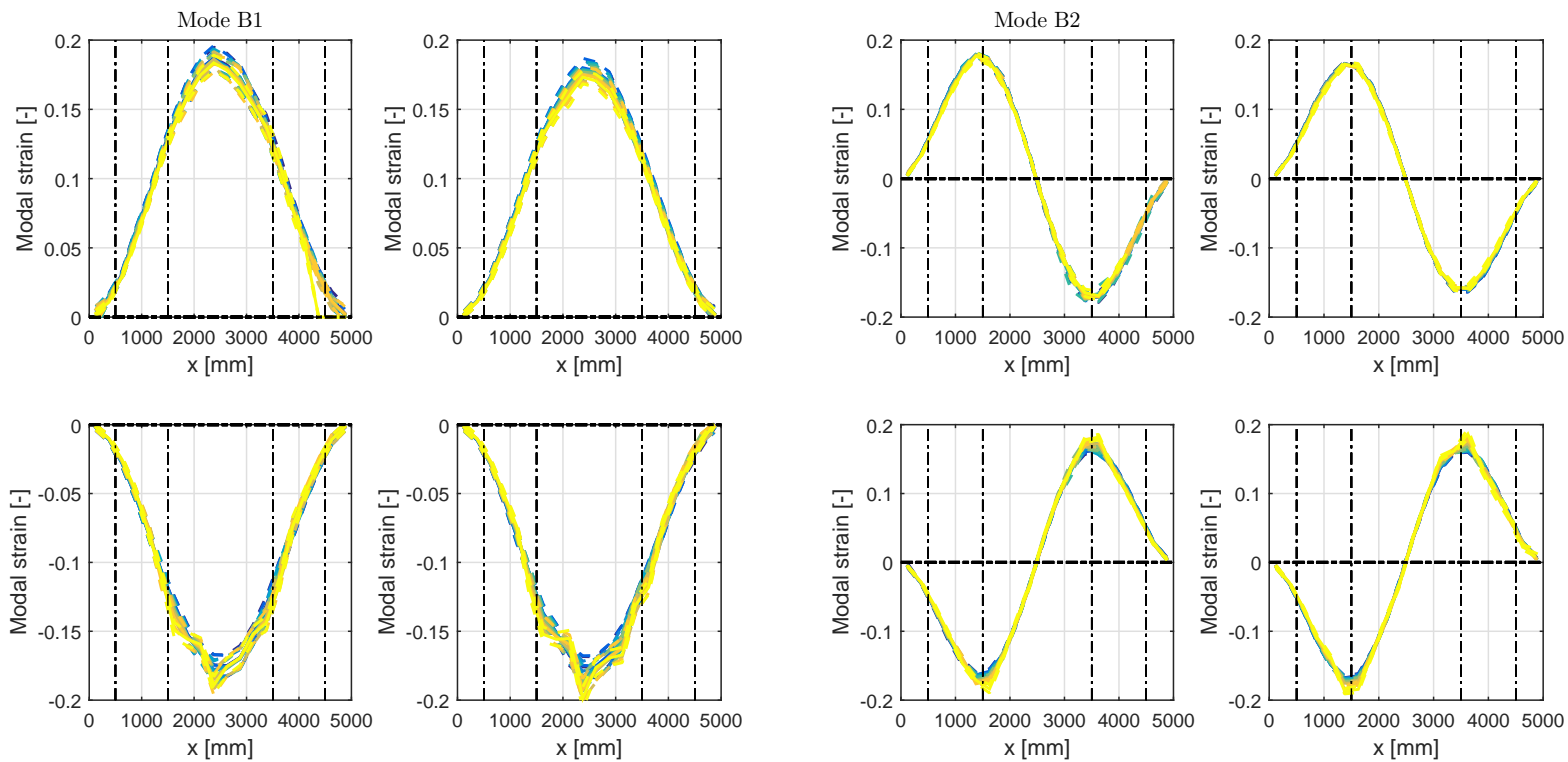

(a)

(b)
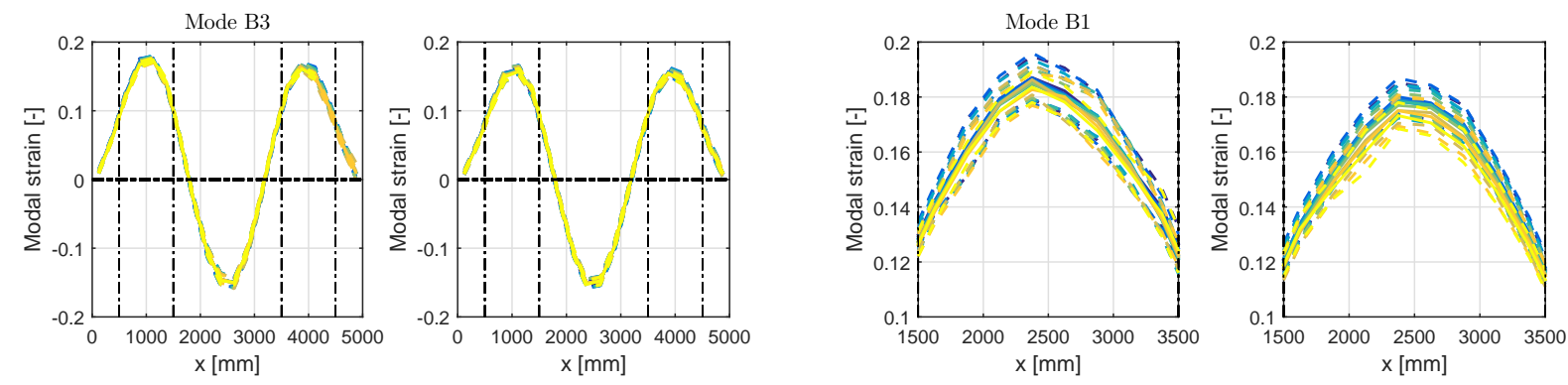

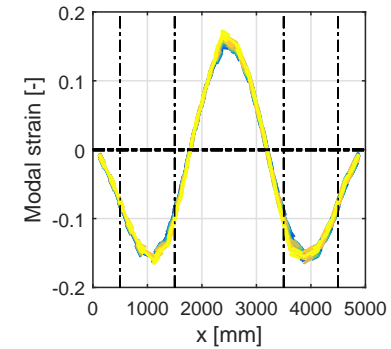

(c)

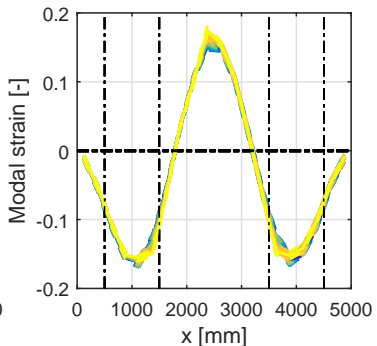

(d)
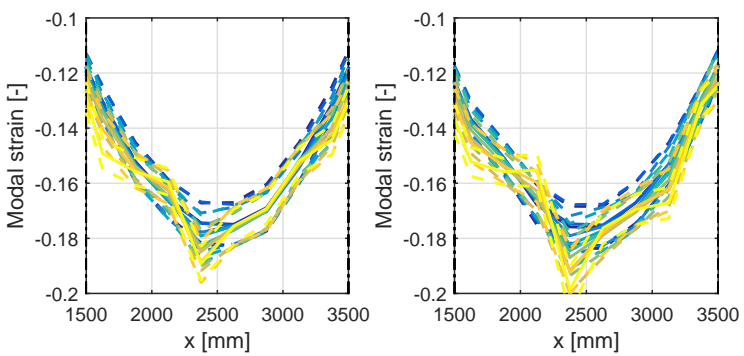

Loading cycle amplitude $2 \mathrm{P}[\mathrm{kN}]$

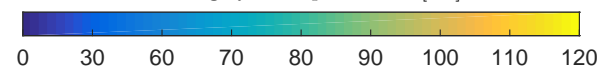

Figure 23: Sample mean $\mu\left[\phi_{2}\right]$ and $95 \%$ confidence interval CI $\left[\phi_{2}\right]$ of the strain mode shapes that have been identified after each loading-unloading cycle of the progressive damage test: (a) first, (b) second, and (c) third bending mode, and (d) zoom of the first bending mode. The $0 \mathrm{kN}$ loading cycle amplitude corresponds to the undamaged beam. The top and bottom subplots contain the strains at the top and bottom sides of the beam (as defined in Fig. 13), respectively. The left and right subplots contain the strains at the sides of the beam with positive and negative y-coordinates, respectively. 
the cracks nearly close after each unloading cycle because of the compressive force provided by the prestressing strands. This renders the present test a very challenging case for modal strain identification. Nevertheless, strain amplitude changes are observed in the vicinity of the damaged area (between the points of the load application) for all modes, as can be seen from the strain mode shapes in Figs. 23 and 24. The largest changes of the modal strain amplitude correspond to the damaged state after the end of the eighth loading cycle at $120 \mathrm{kN}$ (70\% of the failure load at $160 \mathrm{kN}$ ), when the FBG strain sensors were detached from the beam to avoid damaging them during a PDT loading cycle. More specifically, the amplitude of the bottom strain mode shapes is increasing with increasing level of damage at the vicinity of the damaged zone (e.g. Figs. 23d and $24 \mathrm{~b}$ - bottom subplots) and the changes are more prominent at the locations of the cracks (Fig. 11). On the contrary, the amplitude of the top strain mode shapes is decreasing in a uniform pattern at the vicinity of the damaged zone (e.g. Figs. $23 \mathrm{~d}$ and $24 \mathrm{~b}$ - top subplots). This increase/decrease of the strain amplitude for the bottom/top strain mode shapes is related to the shift of the neutral axis of the beam due to the increasing level of damage. Changes in the amplitude of the strain mode shapes are already identified after the end of the second loading cycle with force amplitude of $60 \mathrm{kN}$, when the beam reached its cracking load, indicating early crack identification.
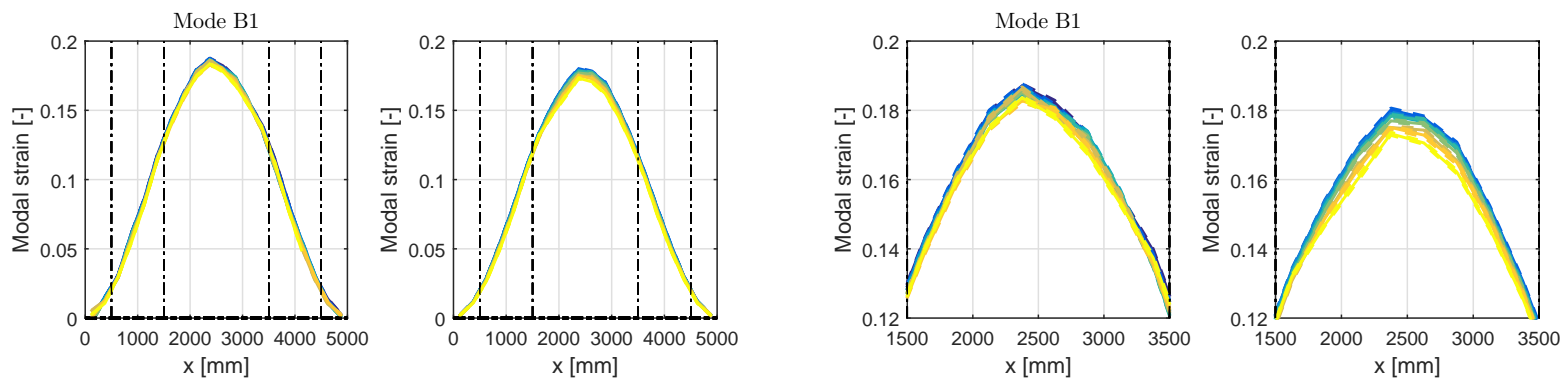

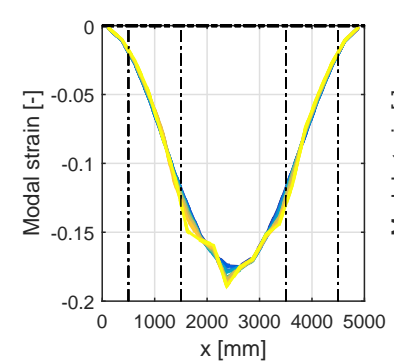

(a)

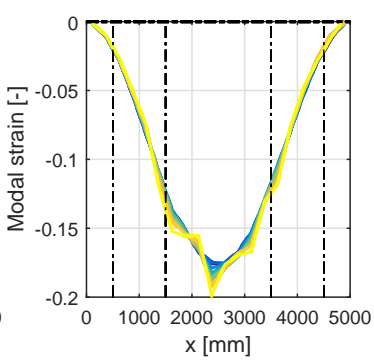

(b)
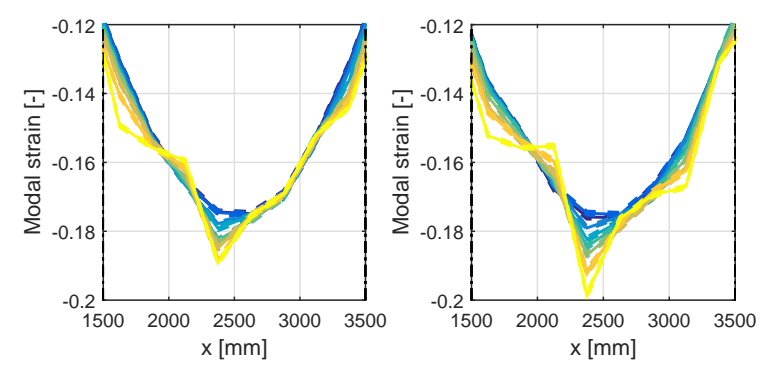

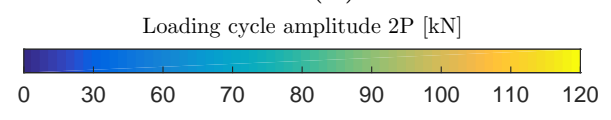

Figure 24: Sample mean $\mu\left[\phi_{2}\right]$ and $95 \%$ confidence interval of the sample mean, $\mathrm{CI}\left[\mu\left[\phi_{2}\right]\right]$, of the strain mode shapes that have been identified after each loading-unloading cycle of the progressive damage test: (a) first bending mode, and (b) zoom of the first bending mode. The top and bottom subplots contain the strains at the top and bottom sides of the beam (as defined in Fig. 13), respectively. The left and right subplots contain the strains at the sides of the beam with positive and negative y-coordinates, respectively. 


\subsection{Influence of damage versus temperature on neutral axis position}

In section 4.2 , the influence of temperature and damage on the modal strain data was investigated in detail. Here, this investigation is extended to the neutral axis position, which can be identified from bending strain mode shapes, as has been discussed in section 2.1.

The influence of temperature on the neutral axis position $z_{\mathrm{N}}$ of the beam is investigated first. Just as for the strain mode shapes, for each temperature group $j$ spanning a temperature range of $2^{\circ} \mathrm{C}$, the sample mean $\mu\left[z_{\mathrm{N}}^{(j)}\right]$, the sample standard deviation $\sigma\left[z_{\mathrm{N}}^{(j)}\right]$ and the $95 \%$ confidence interval $\mathrm{CI}\left[z_{\mathrm{N}}^{(j)}\right]=\left[-2 \sigma\left[z_{\mathrm{N}}^{(j)}\right], 2 \sigma\left[z_{\mathrm{N}}^{(j)}\right]\right]$ are calculated. The mean neutral axis positions of the different temperature groups of the first two bending modes are displayed in Fig. 25, for the second loading cycle (loading amplitude of $60 \mathrm{kN}$ ), where the largest temperature range is recorded. Similar results are obtained for the third and fourth bending modes (B3 and B4) and therefore they are not reproduced here. In addition to the mean values, also the $95 \%$ confidence intervals are provided. Eq. (1) reveals that, at the locations where the modal strains at the top and bottom of a crosssection are both approximately zero (nodal points of the modes), the neutral axis position cannot be accurately obtained. Therefore, Fig. 25 does not contain results for these locations.
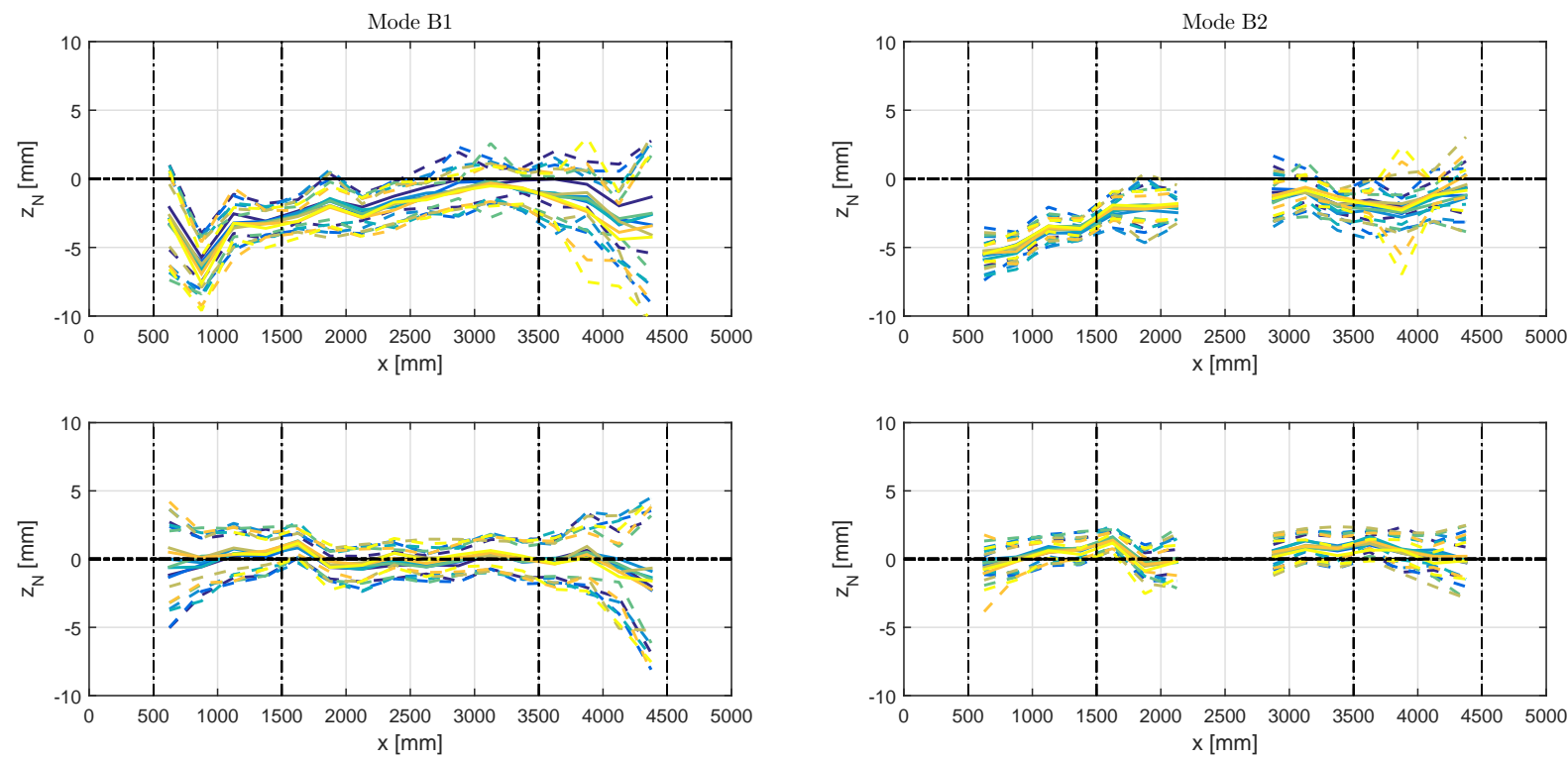

Group temperature $\left[{ }^{\circ} \mathrm{C}\right]$

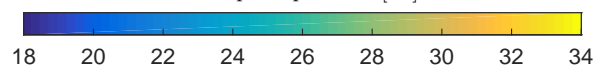

Figure 25: Sample mean $\mu\left[z_{\mathrm{N}}^{(j)}\right]$ and $95 \%$ confidence interval $\mathrm{CI}\left[z_{\mathrm{N}}^{(j)}\right]$ of the neutral axis positions that have been identified in each temperature group $j$, after the $2^{\text {nd }}$ loading cycle $(60 \mathrm{kN})$. The top and bottom subplots contain the neutral axis positions at the sides of the beam with positive and negative y-coordinates, respectively.

The confidence intervals $\mathrm{CI}\left[z_{\mathrm{N}}^{(j)}\right]$ of the neutral axis positions that are obtained at different temperatures overlap completely, and they all have the same width. Hence, in the present experiment, there is no clear influence of the temperature on the neutral axis positions, for the given temperature range of $16^{\circ} \mathrm{C}$.

In a next step, the influence of the progressively applied damage on the neutral axis position is investigated. Since the temperature does not influence the neutral axis positions, all vibration 

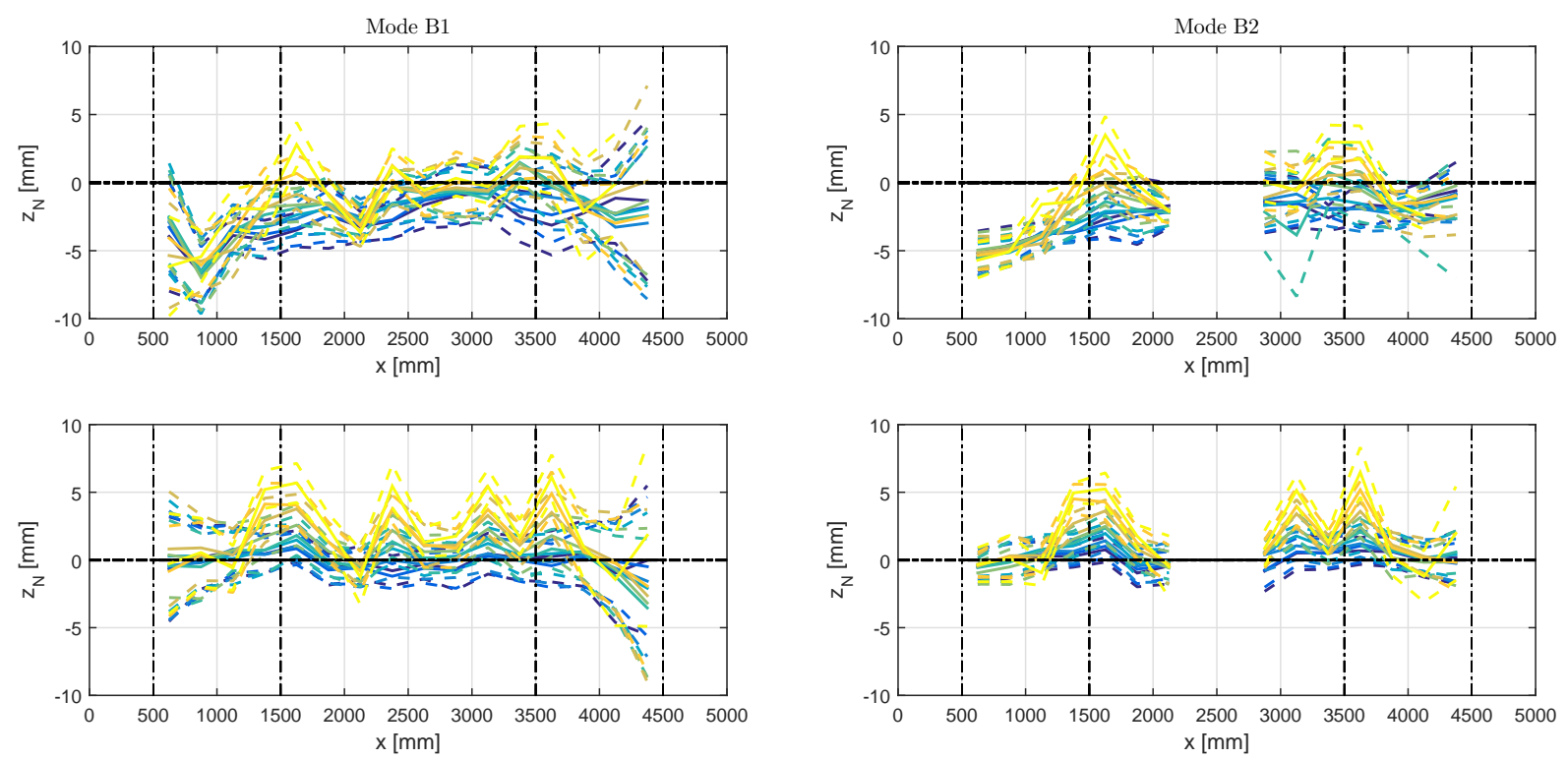

Loading cycle amplitude $2 \mathrm{P}[\mathrm{kN}]$

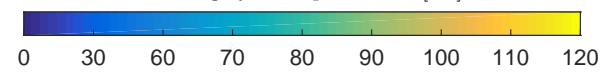

Figure 26: Sample mean $\mu\left[z_{\mathrm{N}}\right]$ (solid lines) and $95 \%$ confidence interval $\mathrm{CI}\left[z_{\mathrm{N}}\right]$ (dashed lines) of the neutral axis positions that have been identified after each loading-unloading cycle of the progressive damage test. The $0 \mathrm{kN}$ loading cycle amplitude corresponds to the undamaged beam. The top and bottom subplots contain the neutral axis positions at the sides of the beam with positive and negative y-coordinates, respectively.

tests (i.e., for all temperature values) performed after a given load cycle are considered together. In Fig. 26, the sample mean of the complete set of identified neutral axis positions $\mu\left[z_{\mathrm{N}}\right]$ that are obtained at a given damage state are plotted, together with the $95 \%$ confidence interval of that set $\left(\mathrm{CI}\left[z_{\mathrm{N}}\right]=\left[-2 \sigma\left[z_{\mathrm{N}}\right], 2 \sigma\left[z_{\mathrm{N}}\right]\right]\right)$. The influence of the progressive damage on the neutral axis positions is clearly larger than the statistical identification uncertainty. Similar results are obtained for the third and fourth bending modes (B3 and B4) and therefore they are not reproduced here.

Just as for the strain mode shapes, the identification uncertainty on the neutral axis positions can be reduced by averaging over repeated identifications, even at different temperatures, given that temperature has no effect. The sample mean of the neutral axis positions, obtained from all modal tests that have been performed after a given loading cycle, are displayed in Fig. 27, together with the $95 \%$ confidence interval of that sample mean. Thanks to the averaging of identification errors in repeated modal tests, the influence of the concrete cracking on the neutral axis positions can be even more clearly observed than in Fig. 26, especially at early stages of damage (low load cycle amplitudes). The first changes already appear after the beam exceeded its crack load at about $50 \mathrm{kN}$ (during the second loading cycle at $60 \mathrm{kN}$ ).

As illustrated above, the neutral axis position can be identified for each bending mode separately. The question then remains how this information can be combined in order to yield a single estimate. A straightforward averaging would be the most obvious choice. However, as discussed above and illustrated in Fig. 26, the identification uncertainty of the neutral axis positions can vary significantly from position to position and from mode to mode. Large uncertainties are expected at zones where the top and bottom strains of a given strain mode shape are both very small (esti- 

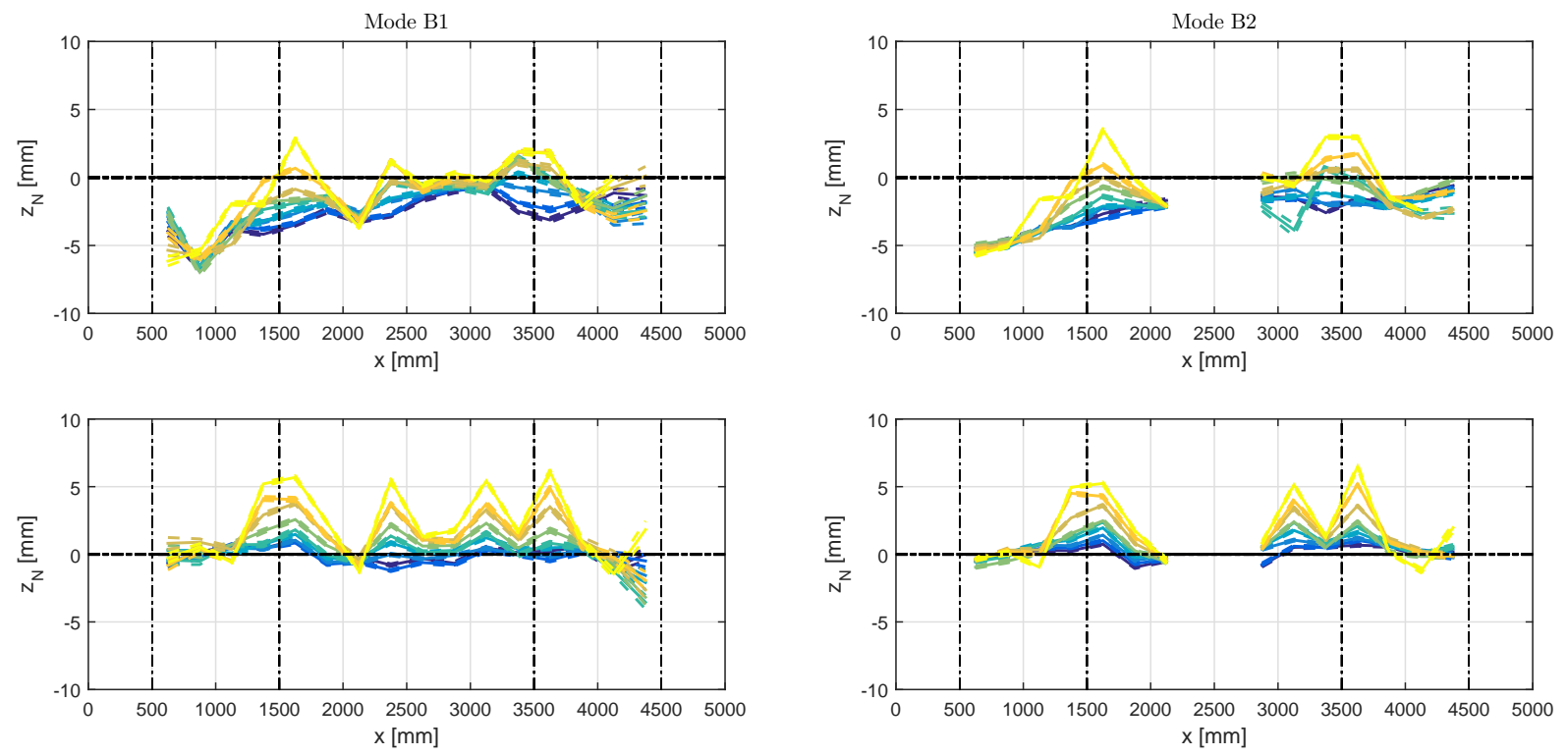

Loading cycle amplitude $2 \mathrm{P}[\mathrm{kN}]$

Figure 27: Sample mean $\mu\left[z_{\mathrm{N}}\right]$ (solid lines) and $95 \%$ confidence interval of the sample mean CI $\left[\mu\left[z_{\mathrm{N}}\right]\right]$ (dashed lines) of the neutral axis positions that have been identified after each loading-unloading cycle of the progressive damage test. The $0 \mathrm{kN}$ loading cycle amplitude corresponds to the undamaged beam. The top and bottom subplots contain the neutral axis positions at the sides of the beam with positive and negative y-coordinates, respectively.

mates with extremely large uncertainties were even excluded from Fig. 26). If these uncertainties are known for each position and each mode, e.g., from repeated modal tests as in Fig. 26, then their inverse values can be used as weights in the averaging process, in order to give most weight to the values with the smallest uncertainties. A maximum likelihood-type averaging [34] for example results in:

$$
Z_{\mathrm{N}, \mathrm{ML}}=\frac{\sum_{m=1}^{n_{\mathrm{m}}} \frac{\mu\left[z_{\mathrm{N}, m}\right]}{\sigma^{2}\left[\mu\left[z_{\mathrm{N}, m}\right]\right]}}{\sum_{m=1}^{n_{\mathrm{m}}} \frac{1}{\sigma^{2}\left[\mu\left[z_{\mathrm{N}, m}\right]\right]}}
$$

where $n_{\mathrm{m}}$ is the number of modes used to calculate the neutral axis position $\left(n_{\mathrm{m}}=4\right), \mu\left[z_{\mathrm{N}, m}\right]$ is the sample mean of the neutral axis position of mode $m$ and $\sigma\left[\mu\left[z_{\mathrm{N}, m}\right]\right]$ is the standard deviation of that sample mean. The standard deviation of the estimated neutral axis position can be estimated as [33]:

$$
\sigma\left[Z_{\mathrm{N}, \mathrm{ML}}\right]=\sqrt{\frac{1}{\sum_{m=1}^{n_{\mathrm{m}}} \frac{1}{\sigma^{2}\left[\mu\left[z_{\mathrm{N}, m}\right]\right]}}}
$$

Besides giving the largest weight to the samples with the smallest uncertainties, $Z_{\mathrm{N}, \mathrm{ML}}$ has the additional advantage that all neutral axis position estimates are included, i.e., zones with very low 
modal strain values do not have to be excluded from the estimation. This is because the neutral axis position estimates in these zones will have a very large uncertainty and therefore they will barely influence $Z_{\mathrm{N}, \mathrm{ML}}$.
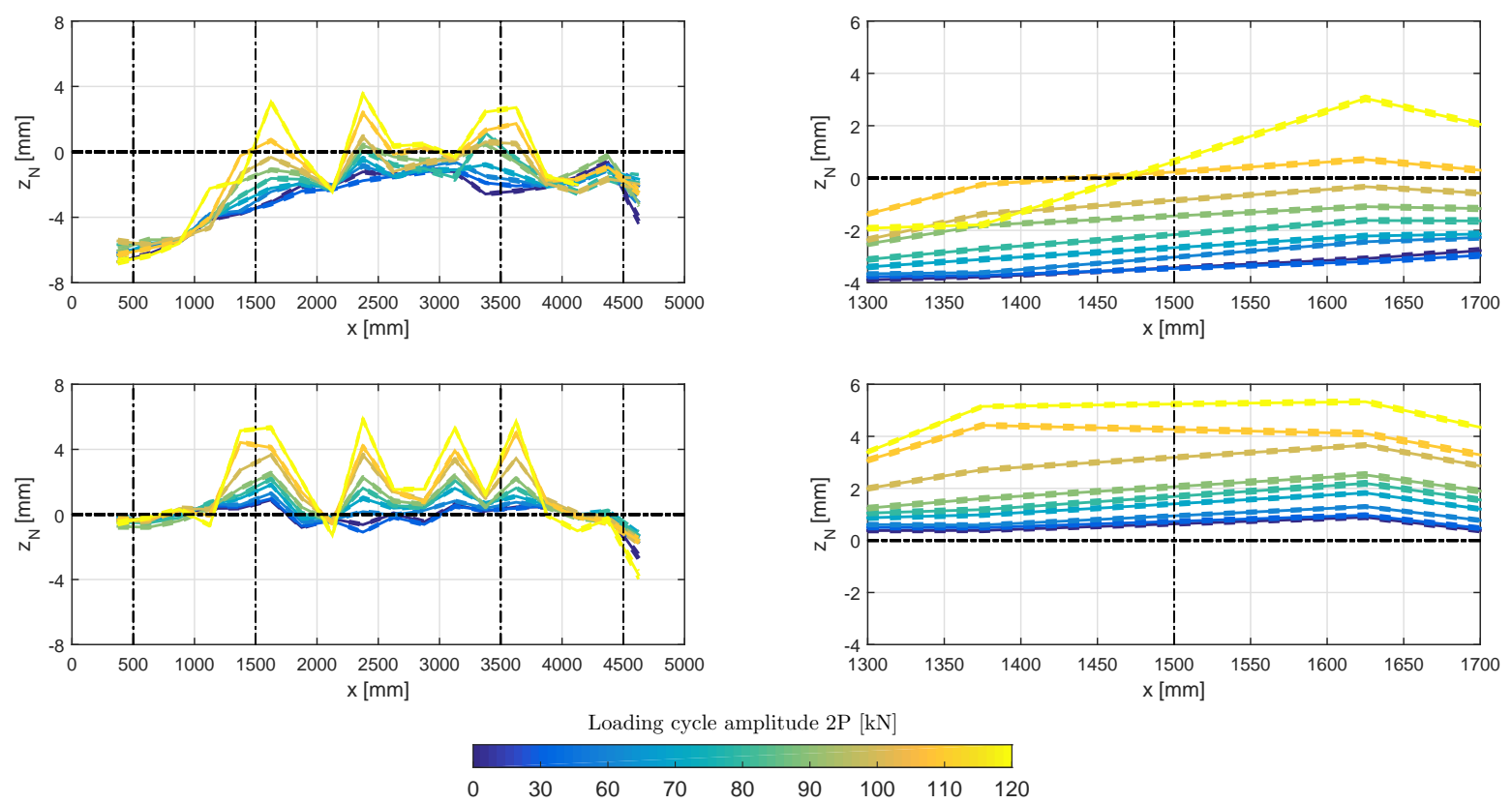

Figure 28: ML estimate of the neutral axis position $Z_{\mathrm{N}, \mathrm{ML}}$ (solid lines) and corresponding $95 \%$ confidence interval $\mathrm{CI}\left[Z_{\mathrm{N}, \mathrm{ML}}\right]$ (dashed lines), as obtained from all model tests performed after each loading-unloading cycle of the progressive damage test. The $0 \mathrm{kN}$ loading cycle amplitude corresponds to the undamaged beam. The top and bottom plots contain the neutral axis positions at the sides of the beam with positive and negative y-coordinates, respectively. The right plots contain a zoom of the left plots.

The maximum likelihood (ML) estimate of the weighted neutral axis position values, together with the $95 \%$ confidence interval $\left(\mathrm{CI}\left[Z_{\mathrm{N}, \mathrm{ML}}\right]=\left[-2 \sigma\left[Z_{\mathrm{N}, \mathrm{ML}}\right], 2 \sigma\left[Z_{\mathrm{N}, \mathrm{ML}}\right]\right]\right)$ is plotted for every damaged state in Fig. 28. Because of the free-free boundary conditions, the modal strains are close to zero at the ends of the beam in all bending modes, such that, despite the weighted averaging, the uncertainty of the neutral axis position estimate $\mathrm{CI}\left[Z_{\mathrm{N}, \mathrm{ML}}\right]$ remains large there. For this reason, the neutral axis position estimates at the beam ends are not displayed. The confidence intervals of the sample mean estimates for each mode were already very narrow (Fig. 27), because they included a large number of samples. After weighted averaging according to Eq. (9), they are even narrower. As a result, shifts in neutral axis position between the different damage states can be very clearly observed in Fig. 28, even at very early damage and despite the near closure of the cracks due to unloading.

Nevertheless, it should be remembered that all statistical estimation errors consist of a bias error and a variance error, and that averaging only reduces the variance error. Although before averaging over all available modal tests per damage scenario (more than 100 tests were performed, at different temperature), the variance errors clearly dominate (cfr. Fig. 26), this is not necessarily the case anymore after averaging as in Fig. 28, and therefore the plotted confidence intervals should be interpreted with care. The relatively small yet statistically significant neutral axis shits that are observed near the beam ends in Fig. 28 are probably due to bias errors. 
As temperature does not have an influence on the neutral axis position in the present test case, it is in principle not necessary to repeat modal tests at different temperatures for a given damage scenario, however, the above analysis has demonstrated that repeated testing is beneficial for reducing the identification variance errors and therefore increasing the chances of detecting damage early. Therefore, the influence of averaging over a small number of repeated modal tests is investigated here. Fig. 29 displays the maximum likelihood estimate of the weighted neutral axis position values, and the corresponding $95 \%$ confidence intervals, when only $N_{\mathrm{s}}=10$ modal tests per loading cycle (randomly selected from all available tests) are included. Although the confidence intervals are clearly larger than in Fig. 28 due to the much smaller number of modal tests included, the shifts in neutral axis position can still be clearly identified, even at early damage states, with high statistical significance.
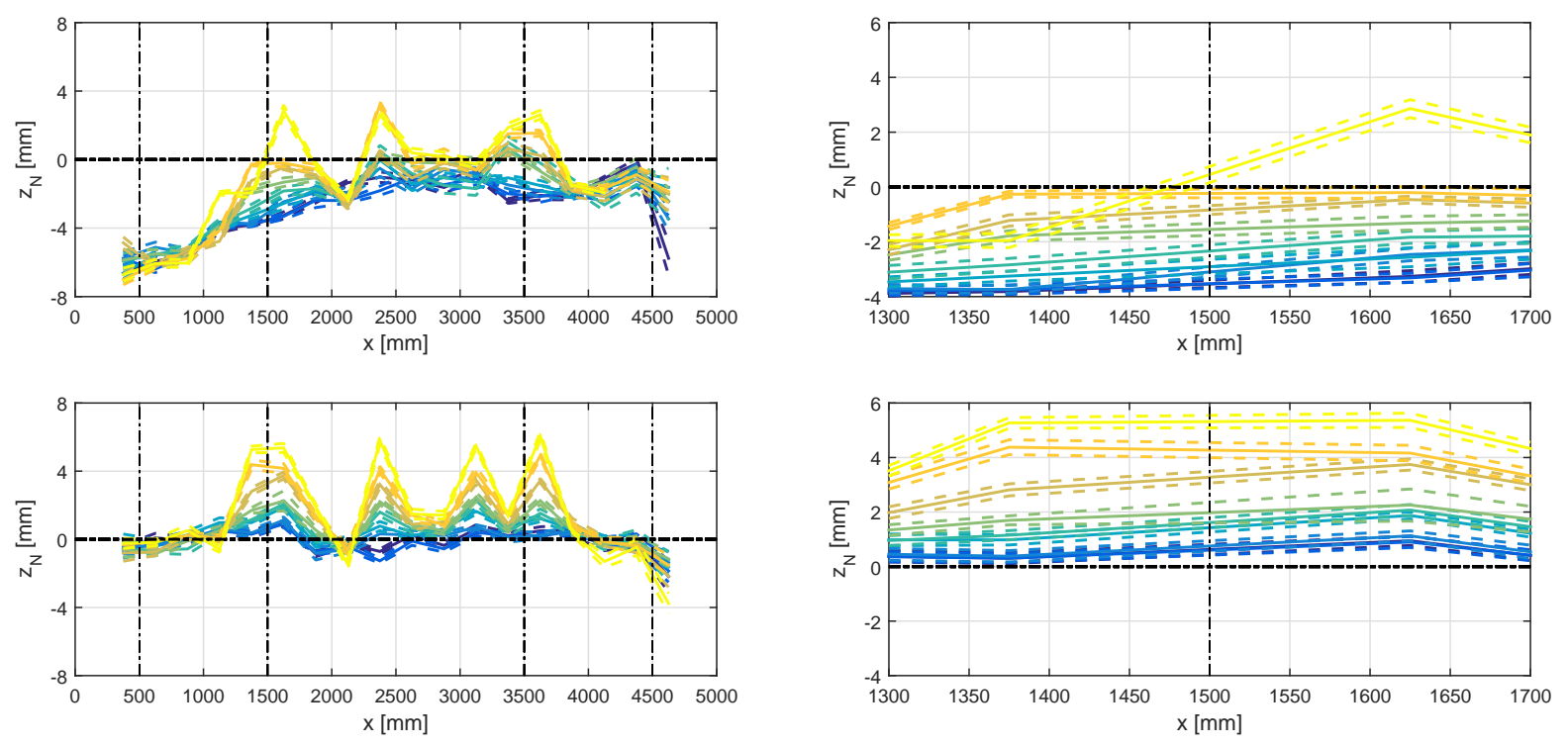

Loading cycle amplitude $2 \mathrm{P}[\mathrm{kN}]$

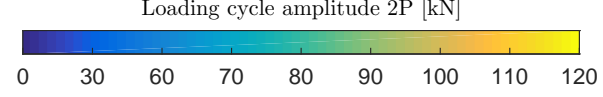

Figure 29: ML estimate of the neutral axis position $Z_{\mathrm{N}, \mathrm{ML}}$ (solid lines) and corresponding $95 \%$ confidence interval $\mathrm{CI}\left[Z_{\mathrm{N}, \mathrm{ML}}\right]$ (dashed lines), as obtained from $N_{\mathrm{s}}=10$ randomly selected model tests performed after each loadingunloading cycle of the progressive damage test. The $0 \mathrm{kN}$ loading cycle amplitude corresponds to the undamaged beam. The top and bottom plots contain the neutral axis positions at the sides of the beam with positive and negative y-coordinates, respectively. The right plots contain a zoom of the left plots.

\section{Concluding remarks}

In this article, two aspects of operational (modal) strain monitoring have been investigated in detail: the processing of strain mode shapes of bending modes into neutral axis positions, and the influence of both temperature and damage on modal strains and neutral axis positions. First, a methodology for computing neutral axis positions under bending deformation from strain mode shapes was presented. Then, a prestressed concrete beam was subjected to an extensive experimental test campaign, in which the beam was gradually damaged in a four-point bending 
progressive damage test involving loading-unloading cycles of increasing load amplitude. After each unloading cycle, temperature changes were induced in the beam, and a strain-based operational modal analysis was performed on the beam for a range of temperature values and in free-free boundary conditions. The excitation level that was applied to the beam resulted in very low dynamic strain RMS values $(0.04 \mu \epsilon)$, similar to the ones occurring on large-scale civil structures. For the acquisition and processing of these very low strain values, an adequate method [19] was employed.

Despite the apparent simplicity of the test structure, it actually represents a very challenging case for vibration-based structural health monitoring, because the dynamic testing is performed in unloaded condition and the self weight of the beam is very small when compared to the external loading. Since it concerns a prestressed concrete beam, cracks are nearly closed during unloading by the compressive forces delivered by the prestressing strands. In most engineering structures such as bridges, this will rarely be the case because the self weight comprises a much larger part of the total loading.

The identified natural frequencies of the test beam were found to be influenced both by damage and by temperature. The influence of temperature was large enough to super-pass the influence of damage and potentially mask its presence. This confirms the necessity of data normalization when natural frequencies are employed as damage-sensitive features.

The strain mode shapes and neutral axis positions were found to be insensitive to temperature changes, regardless of the level of damage in the beam. This is an important conclusion, since a temperature-insensitive dynamic characteristic can be directly used for damage identification, without requiring data normalization. On the other hand, the induced damage had a clear influence on the strain mode shapes and especially on the neutral axis positions that were derived from them. It was also demonstrated that the identification accuracy can be increased by repeating the modal tests a few times and averaging the resulting modal strain or neutral axis position estimates. In this way, also very early damage, which occurred immediately after the cracking load of the concrete, could be detected with high statistical significance.

The findings of this work are very promising for dynamic strain-based structural health monitoring, yet their further confirmation by in-situ testing on a full-scale civil structure, which has more complex boundary conditions and which is subject to more complex temperature distributions as in the laboratory tests presented here, remains necessary.

\section{Acknowledgements}

The research presented in this paper has been performed within the framework of the project G099014N "Robust vibration-based damage identification with a novel high-accuracy strain measurement system", funded by the Research Foundation Flanders (FWO), Belgium. The financial support of FWO is gratefully acknowledged. The authors wish to express their gratitude to Ergon NV for supplying the concrete beam that served as a test object in this study.

\section{References}

[1] C. R. Farrar and K. Worden. Structural Health Monitoring: A Machine Learning Perspective. John Willey \& Sons, West Sussex, U.K., $1^{\text {st }}$ edition, 2013.

[2] J. P. Lynch, C. R Farrar, and J. E. Michaels. Structural health monitoring: technological advances to practical implementations. Proceedings of the IEEE - Institute of Electrical and Electronics Engineers, 104(8):1508-1512, 2016. 
[3] M. M. Ettouney and S. Alampalli. Infrastructure Health in Civil Engineering: Applications and Management. CRC Press, Boca Raton, FL, $1^{\text {st }}$ edition, 2011.

[4] F. Magalhaes, A. Cunha, and E. Caetano. Dynamic monitoring of a long span arch bridge. Engineering Structures, 30(11):3034-3044, 2008.

[5] S. W. Doebling, C. R. Farrar, and M. B. Prime. A summary review of vibration-based damage identification methods. The Shock and Vibration Digest, 30(2):91-105, 1998.

[6] J. M. W. Brownjohn, A. De Stefano, Y. L. Xu, H. Wenzel, and A. E. Aktan. Vibration-based monitoring of civil infrastructure: challenges and successes. Civl Structural Health Monitoring, 1(3-4):79-95, 2011.

[7] W. Fan and P. Qiao. Vibration-based damage identification methods: a review and comparative study. Structural Health Monitoring, 10(1):83-111, 2010.

[8] A. Deraemaeker, E. Reynders, G. De Roeck, and J. Kullaa. Vibration based Structural Health Monitoring using output-only measurements under changing environment. Mechanical Systems and Signal Processing, 22(1):3456,2008

[9] B. Peeters and G. De Roeck. One-year monitoring of the Z24-bridge: environmental effects versus damage events. Earthquake Engineering and Structural Dynamics, 30(2):149-171, 2001.

[10] A. Pau and F. Vestroni. Vibration assessment and structural monitoring of the Basilica of Maxentius in Rome. Mechanical Systems and Signal Processing, 41(1-2):454-466, 2013.

[11] E. J. Cross, K. Y. Koo, J. M. W. Brownjohn, and K. Worden. Long-term monitoring and data analysis of the Tamar Bridge. Mechanical Systems and Signal Processing, 35(1-2):16-34, 2013.

[12] C. Gentile, M. Guidobaldi, and A. Saisi. One-year dynamic monitoring of a historic tower: damage detection under changing environment. Meccanica, 51(11):2873-2889, 2016.

[13] K. Worden and E. J. Cross. On switching response surface models, with applications to the structural health monitoring of bridges. Mechanical Systems and Signal Processing, 98:139-156, 2018.

[14] K. Erazo, S. Debarshi, S. Nagarajaiah, and S. Limin. Vibration-based structural health monitoring under changing environmental conditions using kalman filtering. Mechanical Systems and Signal Processing, 117:1-15, 2019 .

[15] E. Reynders, G. Wursten, and G. De Roeck. Output-only structural health monitoring in changing environmental conditions by means of nonlinear system identification. Structural Health Monitoring, 13(1):82-93, 2014.

[16] J.F. Unger, A. Teughels, and G. De Roeck. Damage detection of a prestressed concrete beam using modal strains. Structural Engineering, 131(9):1456-1463, 2005.

[17] E. Reynders, G. De Roeck, P.G. Bakir, and C. Sauvage. Damage identification on the Tilff bridge by vibration monitoring using optical fibre strain sensors. ASCE J. of Engineering Mechanics, 133(2):185-193, 2007.

[18] A. P. Adewuyi, Z. S. Wu, and N. H. M. K. Serker. Assessment of vibration-based damage identification methods using displacement and distributed strain measurements. Structural Health Monitoring, 8(6):443-461, 2009.

[19] D. Anastasopoulos, M. De Smedt, L. Vandewalle, G. De Roeck, and E. Reynders. Damage identification using modal strains identified from operational fiber-optic Bragg grating data. Structural Health Monitoring, 17(6):1441-1459, 2018.

[20] B. Glisic and D. Inaudi. Fibre Optic Methods for Structural Health Monitoring. John Willey \& Sons, West Sussex, U.K., 2007.

[21] D. Anastasopoulos, P. Moretti, T. Geernaert, B. De Pauw, U. Nawrot, G. De Roeck, F. Berghmans, and E. Reynders. Identification of modal strains using sub-microstrain FBG data and a novel wavelength-shift detection algorithm. Mechanical Systems and Signal Processing, 86A:58-74, 2017.

[22] E. Reynders. System identification methods for (operational) modal analysis: review and comparison. Archives of Computational Methods in Engineering, 19(1):51-124, 2012.

[23] B. Moaveni, X. He, J. P. Conte, and R. A. De Callafon. Damage identification of a composite beam using finite element model updating. Computer-Aided Civil and Infrastructure Engineering, 23(5):339-359, 2008.

[24] S. Li and Z. Wu. A model free method for damage locating and quantifying in a beam like structure based on dynamic distributed strain measurements. Computer-Aided Civil and Infrastructure Engineering, 23(5):404-413, 2008.

[25] U. Haussler-Combe. Computational Methods for Reinforced Concrete Structures. Wilhelm Ernst \& Sohn, Berlin, Germany, $1^{\text {st }}$ edition, 2015.

[26] European Committee for Standardization. ENV1992-1-1:1991 Eurocode 2: Design of concrete structures - Part 1-1: General rules and rules for buildings, 1991.

[27] S. M. O'Connor, Y. Zhang, J. Lynch, M. Ettouney, and G. van der Linden. Automated analysis of longterm bridge behavior and health using a cyber-enabled wireless monitoring system. Proceedings of SPIE, 9063:90630Y1-90630Y11, 2014. 
[28] X. Li and B. Glisic. Integrating finite element modeling with sensing system for monitoring composite structures using the method of neutral axis. Structural Engineering International, 29(1):8-17, 2019.

[29] J. R. Taylor. An Introduction to Error Analysis: The Study of Uncertainties in Physical Measurements. University Science Books, Sausalito, CA, $2^{\text {nd }}$ edition, 1997.

[30] E. Reynders, M. Schevenels, and G. De Roeck. MACEC 3.3: a Matlab toolbox for experimental and operational modal analysis. Report BWM-2014-06, Department of Civil Engineering, KU Leuven, July 2014.

[31] B. Peeters and G. De Roeck. Reference-based stochastic subspace identification for output-only modal analysis. Mechanical Systems and Signal Processing, 13(6):855-878, 1999.

[32] E. Reynders, J. Houbrechts, and G. De Roeck. Fully automated (operational) modal analysis. Mechanical Systems and Signal Processing, 29:228-250, 2012.

[33] E. Reynders, K. Maes, G. Lombaert, and G. De Roeck. Uncertainty quantification in operational modal analysis with stochastic subspace identification: validation and applications. Mechanical Systems and Signal Processing, 66-67:13-30, 2016.

[34] R. A. Fisher. Statistical Methods and Scientific Inference. Hafner Press, New York, NY, $3^{\text {rd }}$ edition, 1971. 